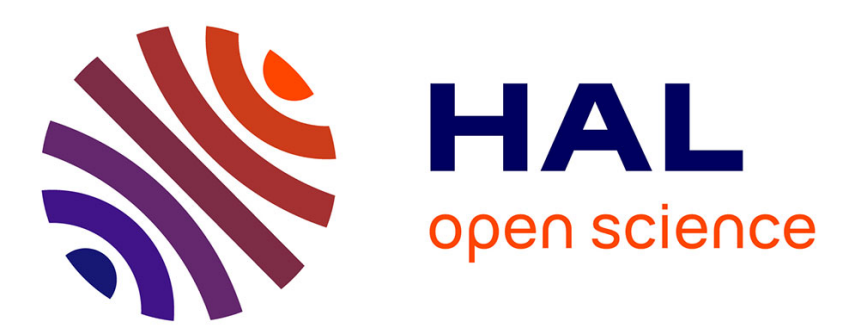

\title{
The role of oxides in the shallow vesiculation of ascending magmas
}

Alain Burgisser, Laurent Arbaret, Caroline Martel, Mélanie Forien, Mathieu Colombier

\section{- To cite this version:}

Alain Burgisser, Laurent Arbaret, Caroline Martel, Mélanie Forien, Mathieu Colombier. The role of oxides in the shallow vesiculation of ascending magmas. Journal of Volcanology and Geothermal Research, 2020, 406, pp.107072. 10.1016/j.jvolgeores.2020.107072 . insu-02955552

\section{HAL Id: insu-02955552 \\ https://hal-insu.archives-ouvertes.fr/insu-02955552}

Submitted on 2 Oct 2020

HAL is a multi-disciplinary open access archive for the deposit and dissemination of scientific research documents, whether they are published or not. The documents may come from teaching and research institutions in France or abroad, or from public or private research centers.
L'archive ouverte pluridisciplinaire HAL, est destinée au dépôt et à la diffusion de documents scientifiques de niveau recherche, publiés ou non, émanant des établissements d'enseignement et de recherche français ou étrangers, des laboratoires publics ou privés. 


\section{Journal Pre-proof}

The role of oxides in the shallow vesiculation of ascending magmas

Alain Burgisser, Laurent Arbaret, Caroline Martel, Mélanie Forien, Mathieu Colombier

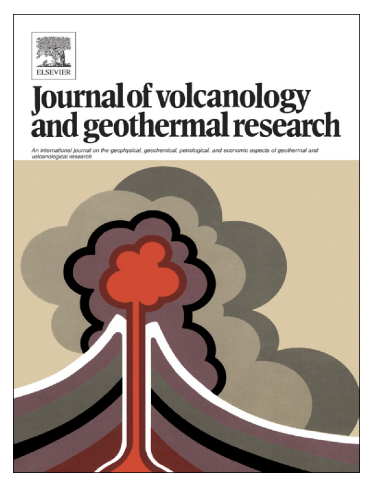

S0377-0273(20)30281-X

https://doi.org/10.1016/j.jvolgeores.2020.107072

VOLGEO 107072

To appear in: Journal of Volcanology and Geothermal Research

Received date: $\quad 23$ May 2020

Revised date: $\quad 24$ September 2020

Accepted date: $\quad 24$ September 2020

Please cite this article as: A. Burgisser, L. Arbaret, C. Martel, et al., The role of oxides in the shallow vesiculation of ascending magmas, Journal of Volcanology and Geothermal Research (2018), https://doi.org/10.1016/j.jvolgeores.2020.107072

This is a PDF file of an article that has undergone enhancements after acceptance, such as the addition of a cover page and metadata, and formatting for readability, but it is not yet the definitive version of record. This version will undergo additional copyediting, typesetting and review before it is published in its final form, but we are providing this version to give early visibility of the article. Please note that, during the production process, errors may be discovered which could affect the content, and all legal disclaimers that apply to the journal pertain.

(C) 2018 Published by Elsevier. 


\title{
The role of oxides in the shallow vesiculation of ascending magmas
}

\author{
Alain BURGISSER ${ }^{1 *}$, Laurent ARBARET ${ }^{2}$, Caroline MARTEL ${ }^{2}$, Mélanie FORIEN ${ }^{3}$, Mathieu \\ COLOMBIER $^{4}$ \\ ${ }^{1}$ Univ. Grenoble Alpes, Univ. Savoie Mont Blanc, CNRS, IRD, IFSTTAR, ISTerre, 38000 \\ Grenoble, France. \\ ${ }^{2}$ Institut des Sciences de la Terre d'Orléans (ISTO), Université d'Orléans, CNRS, BRGM, \\ Orléans, France. \\ ${ }^{3}$ Department of Geosciences, UiT The Arctic University of Norway in Troms $\varnothing$, Postboks \\ 6050 Langnes, 9037 Troms $\varnothing$, Norway.

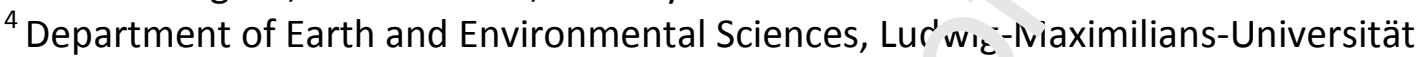 \\ München, Germany.
}

Abstract: 490 words, Main text: 10800 words, 12 Figure. 80 references.

* Corresponding author: Phone: (+33) 479758 7으 Email: alain.burgisser@univ-savoie.fr

\section{Abstract}

Despite their generally low volumu fraction, Fe-Ti oxides have the potential to greatly influence the eruptive style because they love 1 ue supersaturation pressure for heterogeneous bubble nucleation. Once nucleated, bubb'es "espond fast to pressure changes, fostering rapid expansion and explosive behavior. Yet, oxide $\mathrm{n}_{\mathrm{i}}$ icrolite quantifications are often absent from data of explosive products. We used new, 1 -an. lyzed, and published data to build a compilation of oxide number densities (ONDs) and vesic e number densities (VNDs) of trachytic and calc-alkaline products. Four eruptive styles were selected: 1) Vulcanian explosions from Soufrière Hills volcano, Montserrat, Lascar volcano, Chile, and Kilian volcano, France, 2) blasts from Mt Pelée volcano, Lesser Antilles, Mount St. Helens, USA, and Merapi volcano, Indonesia, 3) a sub-Plinian explosion from Merapi volcano, and 4) lava dome effusions with intermittent collapse from Soufrière Hills and Mt Pelée volcanoes. Natural samples were separated into two groups according to the dominant texture of the products of each event: 1) vesicular pumice clasts from explosions with a strong vertical component 
and 2) dense clasts with diktytaxitic textures from dome collapse event and lateral blast. Group 1 samples are either distributed alongside the 1:1 trend between VND and OND that spans from $10^{15}$ to $10^{17} \mathrm{~m}^{-3}$, or have a constant VND of $10^{16-16.5} \mathrm{~m}^{-3}$ regardless of OND. A large proportion of oxides (55$100 \%)$ touch vesicles. A more variable proportion of vesicles (16-72\%) are in contact with oxides because of syn-explosive growth and coalescence. Group 2 samples have ONDs in the same broad range as group 1 samples. We also used new and published data to build a compilation of ONDs and VNDs of five series of experimental decompression of rhyolitic and phonolitic melts. In samples with $\mathrm{OND} \approx \mathrm{VND}$, most bubbles are in contact with more than one oxide ?nd $64-88 \%$ of the oxides are in contact with bubbles. Such high levels of connectivity suggest th th th: role of oxides in controlling bubble nucleation has been underestimated. When $\mathrm{VND} \geq \mathrm{ONL}$, nu leation densities of experimental vesicles can be reproduced by heterogeneous nucleatior $\ldots$-a a is, which we used to calculate synexplosive decompression rates from VNDs at Merapi, 'ouı ì̀re Hills, and Kilian. These rates and textural evidence suggest that the decompression $\mathrm{f}_{\mathrm{O}}$. ar companying these Vulcanian and sub-Plinian explosions is responsible for syn-explosi 'e 1 ubble nucleation. We calculated the average preexplosive ascent rates necessary to yield ' he observed ONDs at Soufrière Hills and Merapi volcanoes. The resulting rates, $0.005-20 \mathrm{~m} / \mathrm{s}$, ove. $12 \mathrm{p}$. unsiderably with the range of critical ascent rate inferred for the effusive-explosive transitw supporting the hypothesis that this transition is primarily controlled by oxide microlites in $l_{i}$ a conduit because oxides are a primer for explosive behavior when present in sufficiently higl nur ber densities. Focusing on the older eruption of Kilian, for which no observation is available, wt infer that pre-explosive ascent rates of $>7 \times 10^{-3} \mathrm{~m} / \mathrm{s}$ were necessary for explosive behavior to occur.

Keywords: Fe-Ti oxides; number density; bubbles; microlite; dome eruption; Vulcanian explosion 


\section{Introduction}

When magma moves upwards into the crust to feed a volcanic eruption, the accompanying change in pressure causes degassing. The process of degassing starts with bubble nucleation, the kinetics of which is controlled by the presence or absence of crystals in the melt. Homogeneous nucleation occurs in pure melts and often requires large pressure changes to induce sufficient volatile supersaturation. Conversely, heterogeneous nucleation of gas bubbles on preexisting crystals can occur following significantly smaller pressure drops. Heterogeneo : nucleation has recently been proposed to be the dominant mechanism occurring in nature ( $\operatorname{Sh} \uparrow, 2(17)$. As a result, attention has been turned towards studying minerals that are able to lower s. ner aturation pressure to the smallest possible values. Minerals belonging to the solid solution of $\mathrm{I}$ - $\mathrm{fi}$ oxides are ideal nucleation sites in this respect. The least effective Fe-Ti oxide is hematite, which reduces supersaturation pressures in rhyolite at $800{ }^{\circ} \mathrm{C}$ from $\sim 200 \mathrm{MPa}$ (homogeneor" nu.uation) to $130 \mathrm{MPa}$ (Cluzel et al., 2008). The most effective mineral is magnetite becausu it ieduces supersaturation pressure to less than $20 \mathrm{MPa}$ (Gardner and Denis, 2004; Gardner, 200/, Shea et al., 2010) or even less than 5 MPa (Hurwitz and Navon, 1994), depending on melt compc it on and temperature. Magnetite crystals play an important role in magmatic systems because th ir large wetting angles cause bubbles to attach to them (e.g., Gardner and Denis, 2004). T'• as $\cdot$ nt of such bubble-magnetite pairs could explain the formation of iron oxide-apatite dep sit. by buoyant segregation (Knipping et al., 2015) and could increase the efficiency of magma mix ${ }^{n}$, by buoyancy-driven stirring (Edmonds et al., 2015).

Magnetite crystals have the potential to greatly influence the style of eruptions involving lavas that are more viscous than those found in to mafic systems. For example, in the case of a melt at water saturation, a magma-filled conduit subject to partial dome collapse is subject to a pressure variation in the order of 5-20 MPa (e.g., Taisne and Jaupart, 2008). This pressure range is similar to the supersaturation pressures causing heterogeneous nucleation on magnetite. Following Cluzel et al. 
(2008) and Cáceres et al. (2020), it is thus reasonable to posit that a magma feeding a dome eruption and bearing large amounts of magnetite microlites would be more prone to nucleate gas bubbles in response to small pressure changes during an eruption than a magma bereft of magnetite. Once nucleated in the conduit, bubbles respond fast to pressure changes (e.g., Lensky et al., 2004; Giachetti et al., 2010) and the ensuing volume changes favor rapid expansion, fragmentation, and explosive behavior. Yet, the hypothesis that magnetite fosters explosive eruptions cannot be tested because of the lack of natural data published in the literature.

Amounts of magnetite in natural samples has typically been (. cumented by reporting volume or modal fractions, which are generally small ( $<5$ vol $\%$ on a but 'le-t ee basis). Bubble nucleation, however, is sensitive to the number density of nucleation sie rat. $\mathrm{r}^{+}$er than to bulk volume or mass fraction of a given mineral. There are, to our knowled e, 1. atural data on oxide number densities (OND) at explosive volcanoes for only one sample fron the 1980 blast at Mount St. Helens, USA (Cashman, 1988), a few samples of Vulcanian ex:-1osiuns at Soufrière Hills, Montserrat (Giachetti et al., 2010; Burgisser et al., 2019), Shinmoeu.'e, Japan (Mujin and Nakamura, 2014), and at Kilian volcano, France (Colombier et al., 201', Extending the scope from explosive eruptions to the reservoir-related sample from the Bishop T.,ff (Gualda and Anderson, 2007) and to the fully degassed Tokachi-Ishizawa obsidian lava 'San et al., 2015) does not vastly extend the amount of available data. This contrasts strongly with the hundreds of samples that have given rise to the numerous published number den` ${ }^{+i}$. of plagioclase and/or pyroxene microlite (e.g., Suzuki and Fujii, 2010; Martel, 2012; Muir et al., ${ }^{\circ}(12)$.

There are more OND data for decompression experiments of water-saturated magmas (e.g., Martel and Schmidt, 2003; Shea et al., 2010), some of them specifically addressing heterogeneous bubble nucleation in the presence of oxides (Hurwitz and Navon, 1994; Gardner and Denis, 2004; Gardner, 2007; Cluzel et al., 2008; Cáceres et al., 2020). That oxide volume fraction is small has been used as a common argument to minimize its role in experimental work addressing bubble growth 
(Burgisser and Gardner, 2004; Cichy et al., 2011; Fiege and Cichy, 2015).

The paucity of natural data hinders the assessment of the role of oxides in the shallow vesiculation of ascending magma. Here, we significantly extend existing data by documenting the OND and vesicle number density (VND) of 105 samples from explosive and effusive products at five volcanoes. Four eruptive styles were selected to evaluate the conjecture that the transition from effusive to explosive eruptions is primarily controlled by the presence or absence of oxide microlites in the conduit. The first style is Vulcanian explosions from Soufrière Hills volcano, Lascar volcano, Chile, and Kilian volcano. The second style is laterally directed blası from Mt Pelée volcano, Lesser Antilles, Mount St. Helens, and Merapi volcano, Indonesia. The $t_{t}$ ird tyle is sub-Plinian convective fountain collapse from Merapi volcano. The last style is lava to ne ffusion with intermittent collapse from Soufrière Hills and Mt Pelée volcanoes. Events fros Soufrière Hills, Kilian, and Merapi volcanoes have been included in this study also becarce the pre-explosive conditions of these sample series (i.e. the pressure and the porosity of each impie in the conduit prior to explosion) have been determined by prior studies (Burgisser et a. 2010; Drignon et al., 2016; Colombier et al., 2017; Burgisser et al., 2019; Colombier et al., sut. nitted).

Natural samples give a spatiz: $1 n k$ vetween oxides and bubbles. Their possible genetic link is often obscured by the many trans $、$ rmations affecting the magma during ascent, evacuation, and final deposition at the surface. We e ected new and published experimental data to aid natural data interpretation and to de "nume the conditions under which oxides can foster heterogeneous bubble nucleation. We chose published decompression experiments with more oxides than nucleated bubbles (Cluzel et al., 2008; Shea et al., 2010) and with more bubbles than oxides (Gardner, 2007; Gardner and Denis, 2004). We present new analysis of three representative samples of experimentally decompressed rhyolite melts (Burgisser and Gardner, 2004) because they have bubbles and oxides in equivalent numbers. Finally, we explore implications of these findings at three volcanoes by showing how oxide nucleation conditions, and thus explosivity, are linked to ascent rate and phase equilibria 
relationships.

\section{Methods}

\subsection{Sample selection}

We used new data, re-analyzed data, and published data to build a compilation of ONDs and VNDs of nine sample series from four volcanoes, totaling 105 individual samples. There are eight new data series. Three series are from Soufrière Hills volcano. One c $f$ them is composed of a selection of the products of Vulcanian explosions in August-October 1997 stuc ied by Burgisser et al. (2010). The two others are from products of block-and-ash flows ge erat d by dome collapse on June 25 , 1997 (Loughlin et al., 2002) and May 20, 2006 (Lough $1 \%$ eı al., 2010), respectively. One sample series was produced by the 1993 Vulcanian eruption at I asc. ${ }^{r}$ volcano (Mattews et al., 1997; Sparks et al., 1997). Two sample series were erupted by $M$. el :e: one during the 1929 block-and-ash flows and the other during the 1902 blast (Marte' et .1., 2000). The last two analyzed series are products from the opening and paroxysmal stages of the 2010 eruption of Merapi volcano, which occurred on October 26 and November 5, respectiv 2l/ ( . . omorowski et al., 2013; Drignon et al., 2016). There is one re-analyzed series from the 94 'ra Vulcanian eruption of Kilian volcano (Colombier et al., 2017; Colombier et al., submitted). Yew and re-analyzed samples are listed in Table S1 in the Supplementary Informatio (. Pu' lished data include products emitted by Vulcanian events on February 11, 2010 (23 samples, Burg sser et al., 2019) and during August-October 1997 (8 samples, Giachetti et al., 2010) at Soufrière Hills, and during the 1980 blast at Mount St. Helens (Cashman, 1988).

We used new and published data to build a compilation of ONDs and VNDs of five series of experimental decompression of rhyolitic and phonolitic melts, totaling 49 individual samples. Published data are from the studies of Gardner and Denis (2004), Gardner (2007), Cluzel et al. (2008), and Shea et al. (2010). In addition, we analyzed three samples of experimentally decompressed rhyolite melts (Burgisser and Gardner, 2004). In their study, Burgisser and Gardner (2004) placed 
samples of rhyolitic glass in sealed Au-capsules with distilled water at $825^{\circ} \mathrm{C}$ and $150 \mathrm{MPa}$ for five days in order to saturate the melt with water. A sudden decompression down to $100 \mathrm{MPa}$ nucleated small bubbles and samples were maintained at the nucleation pressure until bubbles reached approximately thermodynamic equilibrium with a mean diameter of $35 \mu \mathrm{m}$. The analyzed sample (ABG1) was quenched at $100 \mathrm{MPa}$. For the other two samples, pressure was released in increments to approximate a constant decompression rate of $0.5 \mathrm{MPa} / \mathrm{s}(\mathrm{ABG} 16)$ and $1 \mathrm{MPa} / \mathrm{s}(\mathrm{ABG} 28)$ until 50 MPa was reached, at which point the samples were rapidly quenched. For simplicity, the experimentally generated bubbles will sometimes be referred to as vesicles in discussions involving both natural and experimental samples.

\subsection{D imaging}

\subsubsection{Acquisition}

New natural data were collected over sever $d 1, \cdots$ s and quantification methods slightly varied according to sample series. Textural charac ari- ation of samples from Soufrière Hills, Mt Pelée, and Lascar volcanoes was done by imaging pu' 'ished sections by SEM with a JEOL JSM-6400 microscope operating at 15 to $20 \mathrm{kV}$ acceleration vul ag es (ISTO, Université d'Orléans). BackScattered Electrons (BSE) images were acquired at $t^{\prime}$ ire to four different resolutions to ensure that a sufficiently wide range of object sizes was renres ated. Three to four SEM images were acquired at each of the following magnifications: $<25, \times 100, \times 400$, and $\times 800$. One exception is that the $\times 400$ magnification was replaced by $\times 200 \mathrm{fnr}$, amples AMO16C and 1448 that were deposited by the Soufrière Hills block-and-ash flows. For the sample series of Merapi volcano, we used the SEM images at two levels of magnification $(\times 50$ and $\times 2000)$ that have been described in Drignon et al. (2016), where details of the acquisition procedure can be found. The Merapi polished sections were imaged using a TESCAN MIRA 3 XMU SEM operating at 20 to $25 \mathrm{kV}$ accelerating voltage (CNRS-ISTO, Université d'Orléans) in BSE mode. 
One sample from Merapi was imaged by Energy Dispersive Spectroscopy (EDS) as reported in Drignon et al. (2016). Briefly, the polished section was imaged using a LEO STEREOSCAN 440 (LEICA) SEM operating at $15 \mathrm{kV}$ accelerating voltage (Université Savoie Mont Blanc) to which an EDS probe QUANTAX EDS (Bruker AXS) was attached. Distribution maps of Si, Fe, Mg, Al, Ca, K, $\mathrm{Ti}$, and $\mathrm{C}$ were acquired at three to four locations per magnification. The magnifications used were $\times 35, \times 352$, and $\times 2000$ and the resolution of each element map was $512 \times 384$ pixels.

\subsubsection{Processing}

All images were treated using the image processing packages ^ nageJ 1.48 (imagej.nih.gov/ij/) and Fiji 1.52 (Schindelin et al., 2012). Noise reduction was per ${ }^{\prime} r m$ ¿d on the SEM images using ImageJ anisotropic diffusion filter. Segmentation of vesic les ..1d oxides was done by manual thresholding of the lowest and highest levels of gray res) ectively. Plagioclases are difficult to distinguish from glass, impeding calculation of to ${ }^{+\cdots}$ srystal volume fractions based on automatic segmentation (Burgisser et al., 2010). For some Si 'friere Hills samples and all Merapi samples (Table S1), we used vesicularities and total crystal $k$ ume fractions (phenocrysts plus microlite) reported in Drignon et al. (2016) and some crystal voı 'me fractions reported in Burgisser et al. (2010). This is because in both studies, precise segr $\cdot n t_{n}{ }^{+}$on of plagioclases was conducted by manual outlining the plagioclases. In all the other SE' 1 imıdges, we set thresholding values that yielded one segmented phase containing glass, plagio ${ }^{1}$ as $\star$, and all other minerals but oxides. We then manually erased the glass from the thresholind inn ge by visual inspection. Unlike the methods of Burgisser et al. (2010) and Drignon et al. (2016), unis method does not yield outlines of every crystal, which does not affect the accuracy of area fraction but leads to inaccurate size distributions.

Images acquired by EDS were processed with the wavelet "A-trous" filter in ImageJ to decrease the noise level before using the default IsoData thresholding. Objects of interest were obtained by successive subtractions of Boolean combinations of the binary images (Drignon et al., 2016). Vesicles were composed of pixels containing $\mathrm{C}$ or none of the other elements. Oxides were 
composed of pixels containing Fe and Ti but no vesicle pixels.

\subsubsection{Analysis}

For each sample, segmented SEM and EDS images were used to quantify volume fractions and number densities of vesicles, oxides, and other crystals following the resolution assembly procedure of Giachetti et al. (2010). All samples but those of Merapi had similar cut-off values for oxides and vesicles. Images at $\times 25$ magnification were used to characterize objects $1500-8.4 \mu \mathrm{m}$ across, $\times 100$ images were used to characterize objects $267-2.1 \mu \mathrm{m}$ across, $\times 400$ ima $_{c}^{-}$s were used to characterize

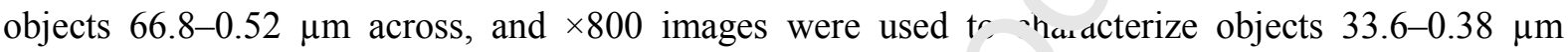
across. The corresponding cut-off values between these sucu ssive magnifications varied between 16 and $100 \mu \mathrm{m}, 4$ and $16 \mu \mathrm{m}$, and 4 and $0.6 \mu \mathrm{m}$, respective:y ('ee Giachetti et al., 2010, for statistical details on image vs. object sizes). Only crystals wi $a$ $n$ equivalent diameter larger than $50 \mu \mathrm{m}$ were counted, except for AMO36, for which oper $\cdots$. 3 s sed all four magnifications with the same cut-off values as for oxides and vesicles. For each Mer $\varkappa_{1} i$ sample, we cropped one $\times 50$ image from the native resolution of $2048 \times 2048$ pixels to $\sim 13 r, \sim \times 1 \supset$ J0 pixels because of the circular shape of the polished sections. The cropped image was us : $d$ characterize objects $1500-20 \mu \mathrm{m}$ across. Four $\times 2000$ images were used to characterize objects $63-0.5 \mu \mathrm{m}$ across with a corresponding cut-off value varying between 30 and $60 \mu \mathrm{m}$ deper- $\mathrm{iti}_{\mathrm{o}}$ un sample.

Object counting and ، haracterization of each magnification was done using the Analyze Particle tool of ImageJ. Our thresholding of SEM images creates false positives of oxides because of the edge effect at the glass/vesicle interface. In some series where the edge artifacts were strong, we eliminated many such false positives on the basis of their cuspate shapes by filtering out objects with circularity $<0.3$. Number density and volume fraction of the objects were then obtained by combining the different levels of magnifications as explained in Giachetti et al. (2010). Both ONDs and VNDs are reported (Table S1) on a bubble- and crystal-free basis (i.e. the number of objects per unit volume of 
glass). Uncertainties on each number density measurement were calculated according to Giachetti et al. (2010) by assuming that $5 \%$ of the number of objects per image were artifacts.

We used the total VNDs and ONDs of the Kilian volcano products reported in Colombier et al. (2017) but adjusted their crystal volume fractions with a combination of XRD analysis and mass balance to calculate bubble- and crystal-free number densities. The SEM image analysis underestimated crystal volume fractions because of the high volume fractions (SI Text 1, Colombier et al., submitted).

\subsection{D imaging}

Relationship between oxides and bubbles can be deter an ${ }^{\circ}$, n $2 \mathrm{D}$ by using statistical analysis of their spatial distribution (Edmonds et al., 2015) but we ised the more direct approach of 3D measurements on representative natural and experimtntal samples. Six samples from the 1997 Vulcanian explosions at Soufrière Hills and thre- saiıples of experimentally decompressed rhyolite melts were imaged by Computed micro- nography $(\mu \mathrm{CT})$ to obtain $3 \mathrm{D}$ volumes of $\mathrm{X}$-ray attenuation levels.

\subsubsection{Acquisition}

The X-ray $\mu$-CT acquisition $\mathrm{f} f$ the experimental samples were performed following the method described in Castro et al. $\left(\mathrm{P}^{n} 1_{2}\right.$, The $3 \mathrm{D}$ volume of ABG1 is the same as that used in Castro et al. (2012) and the volumes $c^{\circ}$ AuB16 and ABG28 are the same as those used in Burgisser et al. (2017). Briefly, scanning was performed with a Phoenix Nanotom 180 (ISTO, Université d'Orléans) with a molybdenum target, a tungsten filament, a variable operating voltage of 100 to $180 \mathrm{keV}$, and a filament current of $50-210 \mathrm{nA}$. We analyzed small $\left(1-4 \mathrm{~mm}^{3}\right)$ chips of vesicular glass by mounting them onto carbon fiber rods with thermoplastic adhesive. Samples were rotated over $360^{\circ}$ during the exposure to the X-radiation. Between 1300 and 2300 images of $2304 \times 2304$ pixels were collected during each analysis. Reconstruction of these images into a stack of grayscale images representing 
different phases was performed with a separate PC microcluster running Phoenix reconstruction software. This piece of software includes a proprietary ring artifact correction procedure based on averaging and subtraction of blank images taken during acquisition by temporarily removing the sample from the field of view. The voxel edge length was $2.2 \mu \mathrm{m}$ for ABG1, $1.9 \mu \mathrm{m}$ for ABG16, and $1.5 \mu \mathrm{m}$ for $\mathrm{ABG} 28$.

The $\mu$-CT acquisitions of the natural samples were performed at the TOMCAT beamline of the SLS synchrotron facility (Villigen, Switzerland; Stampanoni et al., 2006) following the procedure described in Degruyter et al. (2010). The imaged samples were smi. ' volumes of rock immediately adjacent to those forming the polished sections imaged by SEM to $r$ inimize the effects of spatial variability. The beam energy was varied between 20 and $25 \mathrm{k}>\mathrm{S}$. mples were rotated over $180^{\circ}$ and between 1000 and 3000 projections were taken per sc $\varepsilon$. $t$. field of view of $5.5 \times 5.5 \mathrm{~mm}^{2}$ and a resolution of $2048 \times 2048$ pixels were used. Reconstruntions or the $3 \mathrm{D}$ volumes were done using the in-house software developed at the synchrotron $b=$ amıme, yielding a voxel edge length of $2.7 \mu \mathrm{m}$. No ring artifact correction was needed.

\subsubsection{Processing}

All volumes were treated $\mathrm{u}, \mathrm{n}_{\mathrm{s}}$ ImageJ and Fiji. They were converted to stacks of 8 -bit grayscale images, and were then ropped into cuboids for further analysis. Noise reduction was performed on most volume wa the wavelet "A-trous" filter, and with the "anisotropic diffusion" filter on the remaining vo: 'mes. The filtered image stacks were converted to binary format by manual thresholding of the highest and lowest levels of gray to segment oxides and vesicles, respectively. Sub-volumes were cropped so that no sample edge was present in the volume of interest (VOI). This yielded VOIs of $\sim 1000^{3}$ voxels for natural samples (Table S2). The small sizes of the experimental samples (Burgisser et al., 2017) constrained us to use VOIs $<600^{3}$ voxels. Details on 3D rendering parameters are in Text S2. 


\subsubsection{Analysis}

Oxides and vesicles were counted using the "Particle Analyzer" tool of the BoneJ plugin (Doube, 2020) of ImageJ. The minimum size of all objects was set to 10 voxels for natural samples. No scan at higher resolution was available, and the consequences of this lower limit are assessed in section 2.4. The simple texture of the experimental samples allowed us to tailor the minimum size of counted bubbles to 27 voxels. Resulting bubble mean diameters in the analyzed VOIs are $25 \mu \mathrm{m}$ for ABG1 and $66 \mu \mathrm{m}$ in ABG 16, which are comparable to the values reported in Burgisser and Gardner (2004): $35 \pm 7$ and $71 \pm 8 \mu \mathrm{m}$, respectively.

To test whether the VOIs of the experiments had sufficient $r n^{-1}$, tion to capture the fine end of the oxide size distribution, we used the ABG28 volume liecaine it was acquired at the highest resolution (voxel edge length of $1.5 \mu \mathrm{m}$ ). The three sam ${ }_{1}^{-1} \mathrm{es} \checkmark$ ere extracted from the same $\sim 100 \mathrm{~cm}^{3}$ block of obsidian glass and are part of similar decor ${ }^{2}$ 'ssion series that did not nucleate new crystals (Burgisser and Gardner, 2004). The only sourre $f$ differences in the size distributions of the three samples is natural variability within the origl. 1 obsidian glass block. The minimum size of counted oxides was 8 voxels for ABG1 and ABC16. Thanks to a less noisy stack (Fig. S1), oxides in ABG28 were counted with a lower threshold of 4 . uxels. Figure 1 shows the resulting size distribution, which can be used to estimate the numb , ${ }^{r}$ of uxides that were too small to be captured by the $\mu \mathrm{CT}$ scan. We carried out this extrapolation $b_{\text {, }}$ fir st fitting a power law curve to the fine end of the distribution (15$\left.400 \mu \mathrm{m}^{3}\right)$. We then ust. ${ }^{1}{ }_{1}:-$ it $\left(\mathrm{R}^{2}=0.99\right)$ to calculate the putative cumulative number of oxides between $15 \mu \mathrm{m}^{3}$ and the single oxide of $0.023 \mu \mathrm{m}^{3}$ predicted by the power law. Results indicate that 152 oxides $<15 \mu \mathrm{m}^{3}$ could be present in the ABG28 VOI. As we measured 8553 oxides in that VOI, the number of oxides could thus have been underestimated by $1.7 \%$. Figure 1 also shows the limits of the smallest oxides analyzed in the two other samples. Applying the same reasoning to those samples, our analysis thus captured $83 \%$ and $88 \%$ of the oxides present in ABG1 and ABG16, respectively. This source of positive uncertainty is larger than the one stemming from calculating the standard 
deviation between VOIs of different sizes (see below).

Calculating number densities in 3D is more straightforward than in 2D. The numbers of oxides, $N_{o x}$, and vesicles, $N_{v e s}$, in the analyzed volumes were divided by the volume of glass (i.e. the total volume minus that of the vesicles and that of the oxides) to obtain ONDs and VNDs, respectively (Table S1). This was done only for the experimental samples because their unimodal bubble size distributions were fully captured within the VOIs. Giachetti et al. (2011) have shown that obtaining accurate ONDs and VNDs in natural samples requires combining stacks of different resolutions and an automated de-coalescence of the connected vesicle network. Sucı analysis is beyond the scope of our study, and we used their values instead (Table S1).

The level of connectivity between vesicles and oxides is a measure of how many oxides are in close contact with vesicles and vice-versa. In each VOI, $\mathrm{c}$. ides were dilated by 1 voxel and counted to obtain the number of dilated oxides, $N_{o x-d}$. Dilatio $\ldots$ necessary because when a voxel contains a vesicle-oxide contact, the contrast in X-Ray ${ }^{\prime \prime} \cdot n u^{-}$tion between the mineral and the vesicle yields an average value of attenuation that is segmente in neither phase. The volume containing the dilated oxides was combined with the volume crat ing the segmented vesicles so that the result is a volume containing segmented objects that Ic eluler isolated vesicles, or isolated oxides, or oxide-vesicle pairs. In other words, the Boolea. operator or was applied between the volume with dilated oxides and that with vesicles. As the $\mu^{\curvearrowright T}$ scans had similar resolutions, dilation assumes overall that oxides closer than about $2 \mu \mathrm{m} \hbar \mathrm{m}$ vesicles are connected to these vesicles. Objects in the resulting volume were counted to obtain the total number of objects, $N_{\text {tot }}$, which comprises isolated vesicles, isolated oxides, and connected oxide(s) and vesicle(s). The number of connected objects was defined as: $N_{c o n n}=N_{o x-d}+N_{v e s}-N_{t o t}$. The levels of connectivity of oxides and vesicles are measured by the ratios $N_{\text {conn }} / N_{o x}$ and $N_{\text {conn }} / N_{\text {ves }}$, respectively. Values $>1$ mean that each object of the considered phase is connected to several objects of the other phase. Figure S2 illustrates these two measures of connectivity and their limitations. Text S3 details the error propagation of the lower detection limit of 
oxides on $N_{c o n n} / N_{o x}$ and $N_{c o n n} / N_{\text {ves }}$.

To determine whether our VOIs were representative elementary volumes (REVs), we measured levels of connectivity in VOIs of progressively smaller sizes. To reduce computing time, this was done by using an object counting method based on object centroids (see Fig. S3 for details). Figure 2 shows the level of connectivity of oxides, $N_{c o n n} / N_{o x}$, measured in a series of volumes of progressively smaller sizes. Volumes with $>10^{8}$ voxels for natural samples and $>10^{7}$ voxels for experimental samples are statistically representative because they are above the size at which fluctuations between different volumes stabilize. This difference in minimum REV size 1, due to the fact that the largest natural vesicles are larger than their experimental counterparts. . igur $: 2$ shows that all the largest VOIs (Table S2) are REVs. We thus report the levels of connf cl rit measured on the largest VOIs for all samples. We used the standard deviation of the three 1 rrge $t$ VOIs to estimate uncertainties on the connectivity of natural samples. The minimum errnr of the experimental samples was also the standard deviation of the three largest VOIs. T he nuaximum error of the experimental samples, however, was that due to the lower detection $:{ }^{*}$ it of oxides (Text S3).

In natural samples, because segr 'nta: on of glass and other crystals in the $\mu \mathrm{CT}$ volumes is challenging, we opted to use the cry'ta: cuntents from the SEM analysis. In experimental samples, FeTi oxide is the only mineral phase $\cdot$ nd is easy to segment.

\subsection{Measurement эcc uracy}

The procedure of Giachetti et al. (2010) retrieved vesicle size distributions with great accuracy because it used 6 overlapping levels of magnification and a step of vesicle de-coalescence (i.e. closing manually partially retracted walls between neighboring vesicles) to reconstruct these distributions. This high accuracy was obtained at the expense of a labor-intensive, time-consuming process. One goal of our analysis procedure was time efficiency, which guided the choice of the number of magnifications and that of minimizing manual operations during image analysis. The result of these 
choices was to maintain the accuracy of the OND and VND determinations at the expense of a loss in the resolution of object size distributions.

Figure 3 shows object number densities for one characteristic pumice sample, AMO36, that were determined using three different segmentation procedures. The first procedure is that of Giachetti et al. (2010), which yields accurate OND and VND that we use as reference values. The second procedure (Giachetti et al., 2011) combined 3D $\mu \mathrm{CT}$ data from multiple image stacks with different spatial resolutions to generate vesicle size distributions. The third procedure is our 4magnification levels method, which was applied on AMO36 by three tifferent human operators using slightly different combinations of segmentation thresholds and cut- ff $\mathrm{v}$ ،lues between magnifications.

The multiscale 3D data of Giachetti et al. (2011) yield , VIV similar to that measured on SEM images, but an OND that is $1.5 \log$ units below that fron. SEN images (Fig. 3). This has been shown by Giachetti et al. (2011) to be resulting from the co $\mu$ s ratively lower resolution of the $\mu \mathrm{CT}$ imaging, which imposes a lower minimum cut-off valı_- $3.4 \mathrm{\prime m})$ compared to the SEM image $(0.38 \mu \mathrm{m})$. The $\mu \mathrm{CT}$ reconstructions thus fail to image the sma ${ }^{2}$ 'st oxides, which are present in high number densities in that sample. The SEM vesicle separ ${ }_{\text {: }}$ on procedure of Giachetti et al. (2011) includes a step of vesicle de-coalescence, whereas ou is ines not. Figure 3 shows that the absence of de-coalescence does not affect results because th smallest, most numerous vesicles are generally isolated and not subject to de-coalescence. $\Gamma_{\cap n} \cdot{ }^{-A}$ ring the SEM image magnifications we used, objects larger than 1.5-3 mm across are exp 'teu to be missing from our size distributions (Giachetti et al., 2010). This is not an issue for the generally smaller oxides, but it strongly affects vesicle volume distribution as vesicles larger than $1.5 \mathrm{~mm}$ occupy up to a quarter of the volume of void (Giachetti et al., 2010). Cumulated number densities, however, are not affected by the upper size limit because large vesicles are far less numerous $\left(10^{8}-10^{10} \mathrm{~m}^{-3}\right)$ than smaller ones $\left(10^{15}-10^{16} \mathrm{~m}^{-3}\right)$. This is visible in Fig. 3, which shows that the reference size distributions determined by Giachetti et al. (2010) and those obtained with our method yield similar cumulated number densities. All our analyses involve 4 magnification 
levels, except those of Merapi products and those of the February 2010 Soufrière Hills explosive products that only involve two magnification levels. It has been shown in Drignon et al. (2016) and Burgisser et al. (2019) that cumulated number densities in these samples are unaffected by the artifacts introduced by this information gap because the smallest and most numerous objects are captured by the highest SEM magnification.

Another issue is that oxides have been shown to be very small in products of explosive eruptions, reaching nanolite sizes (Mujin and Nakamura, 2014). Compared with the SEM procedure, the EDS procedure is able to capture smaller oxides because oxides 1 . ve a chemical composition that is distinct from that of the other minerals. Figure 3 shows that EDs bas d images of sample AME10G with a cut-off limit of $0.1 \mu \mathrm{m}$ yield an OND that is $1 \log$ uni $h_{r}{ }^{r} h r$ than that of SEM images with a $0.38 \mu \mathrm{m}$ cut-off. That more oxides are found at a lower $\mathrm{c}^{\prime \prime}$-oft is consistent with the presence of oxide nanolites in our samples. This suggests that our JL $A$-based ONDs with a $0.38 \mu \mathrm{m}$ cut-off are minimum values because Mujin and Nakamı $(\llcorner\urcorner 14)$ report oxide nanolites of $0.01-0.02 \mu \mathrm{m}$. The $\mu \mathrm{CT}$ reconstructions of natural samples undes stimate natural ONDs by an additional one order of magnitude. This is not the case for $\exp ^{\text {: }}$ mt tal samples because the $\mu \mathrm{CT}$ scans capture $83-98 \%$ of the oxides (Fig. 1).

Finally, EDS images with the ame $0.38 \mu \mathrm{m}$ cut-off limit as the SEM images yield an OND that is $1 \log$ unit lower than the o1 SEM images. This counter-intuitive result is due to our thresholding of SEM images, which creatc false positives because of vesicle edge effects that a circularity filter limits but does not suppress. The remaining false positives (i.e. bubble edges incorrectly counted as oxides) compensate somewhat the loss caused by the high cut-off value, but do so in a way that is difficult to quantify.

The intrinsic errors of the different methods are much smaller than inter-operator variability (Fig. 3). We thus based the overall uncertainties of our number densities on the maximum differences between the four SEM determinations of Fig. 3, which correspond to $\pm 0.13 \log$ units for oxides and 
$\pm 0.15 \log$ units for vesicles, and we consider our ONDs as minimum values. We applied those two levels of uncertainty due to inter-operator variability to all samples analyzed in $2 \mathrm{D}$, regardless of their origin (new, re-analyzed, or published).

\section{Results}

\subsection{Vesicle types and oxide-vesicle contacts}

Vesicles in our natural samples were subdivided in sub-r onulations using the criteria of Giachetti et al. (2010). There are two main types of small $\left(<30-5 C \mu \mathrm{m}_{\mathrm{t}}\right.$, vesicles. The first type, $\mathrm{S} 1$, is composed of rounded, isolated vesicles that occur in vesicula sar ples (Fig. 4A), such as the ones described in Giachetti et al. (2010) and Burgisser et al. (2 : १). The second type, S2, is composed of irregular voids often delimited by crystal faces that occur in '``nse samples with a diktytaxitic texture (Fig. 4B). A couple of samples feature both typ s (rir,. 4C). One sample from Mt. Pelée features deflated vesicle textures such as narrow, pir her' -off necks connecting two flattened vesicles (Fig. S4) associated with bubble collapse (e.g., Ac' 'ms et al., 2006; Moitra et al., 2013; Pistolesi et al., 2015). We did not find in our samples bubble zr $1 k$ pse textures linked to shear-bands (Wright and Weinberg, 2009). There are three types of la $g_{c}(>30-50 \mu \mathrm{m})$ vesicles. Two of them are composed of deformed vesicles of equivalent size $>300, \mathrm{~m}$ across and circularity $<0.2$. Type L1 comprises large angular voids between crystal fr. gme its that are interpreted to have been formed in response to the decompression accompanvi g the Vulcanian explosion (Giachetti et al., 2010; Burgisser et al., 2010; Burgisser et al., 2019). Type L2 is composed of the remaining vesicles of $>300 \mu \mathrm{m}$, which are considered as pre-explosive vesicles. Type L3 is composed of 40-300 $\mu \mathrm{m}$, lobate vesicles that result from newly nucleated S1 bubbles that have undergone some growth and coalescence (Giachetti et al., 2010).

On the basis of 2D observations, the first small vesicle type S1 has been often associated with 
oxides (e.g., Giachetti et al., 2010) and represents the latest syn-explosive nucleation event. Here we extend these observations to 3D by looking at the proportion of oxides that are touching S1 vesicles (or in close proximity of $<3 \mu \mathrm{m}$ ) and vice-versa. Figure 5 shows the fractions of oxides and vesicles that are in close contact with one another. In natural samples bearing S1 vesicles, the level of oxidevesicle connectivity ranges from $55 \%$ to $100 \%$ and the level of vesicle-oxide connectivity ranges from $16 \%$ to $72 \%$. In other words, half to all oxides touch vesicles whereas a smaller and more variable proportion of vesicles are in contact with oxides. Figure $6 \mathrm{~A}-\mathrm{B}$ shows $2 \mathrm{D}$ and $3 \mathrm{D}$ renderings of a representative sample with an oxide-vesicle connectivity of $90 \%$ and a vesicle-oxide connectivity of $16 \%$. It illustrates that most oxides are protruc ing nside vesicles whereas most vesicles contain no oxides.

Because it is the hallmark feature of the diktytaxiti tex are, S2 vesicles are mostly observed in samples with that texture, although we observe a cor:inuum between the proportions (and shapes) of S1 and S2 vesicles in our samples (Fig. 4). We nc $\cdot$ that none of the classical shape indicators such as circularity, elongation, or shape factor $\Omega$ ( $\Omega_{-}$tra et al., 2013) could reliably discriminate the two vesicle types in $2 \mathrm{D}$ images. Although in co ${ }^{\text {tact }}$ with oxides $(16 \%$ of the vesicles of the diktytaxitic sample of Fig. 5 touch oxides), S2 vf $\mathrm{lt}_{\mathrm{c}}$ are mostly found in low-porosity dome samples and blockand-ash flow products. One like v origin of these vesicles is reorganization of voids under shear (Laumonier et al., 2011). Here ve imply assume that the number density of S2 vesicles is not caused by nucleation and that is a $\mathrm{r}_{\mathrm{n}}$ chus no genetic link between oxides and S2 vesicles. This leads us to consider block-and-ash liuw products separately from those issued from ash fallout or fountain collapse.

The decompression experiments of Burgisser and Gardner (2004), which involve rhyolitic melt bearing $<0.1$ vol.\% oxides, provide additional constraints on the relationship between bubbles and oxides. Figure 5 indicates that $\sim 100 \%$ of the bubbles are in contact with an oxide in ABG1. In the two other samples, $155-215 \%$ of the bubbles are in contact with an oxide, which means that bubbles 
touch, on average, 1.6-2.2 oxides. This connectivity increase is most likely due to bubble growth because bubble size goes from $25 \mu \mathrm{m}$ in ABG1 at a quench pressure of $100 \mathrm{MPa}$ to $56-66 \mu \mathrm{m}$ in ABG16 and ABG28, which were both quenched at $50 \mathrm{MPa}$ (Burgisser and Gardner, 2004). Conversely, $64 \%$ to $88 \%$ of the oxides touch experimental bubbles, indicating a high level of connectivity (Fig. 6C). As shown below, these levels of connectivity are consistent with the comparable VND and OND values of this experimental series.

\subsection{Vesicle and oxide number densities}

Figure 7 shows vesicle and oxide number densities of all ur s mples plus samples from the literature. Figure 7A indicates that the nearly aphyric glasses fr $\mathrm{m}$ e periments have number densities spanning from $10^{10}$ to $10^{16} \mathrm{~m}^{-3}$. Samples in Fig. $7 \mathrm{~A}$ car $\mathrm{u}$ a vided into three categories: samples featuring more oxides than bubbles such as the series of Cluc al et al. (2008) and Shea et al. (2010), samples with more bubbles than oxides such as he ce les of Gardner (2007) and most samples of Gardner and Denis (2004), and samples wit - br sbles and oxides in equivalent numbers such as those of Burgisser and Gardner (2004).

Natural samples were divided into tw, o categories according to the dominant texture present in the samples from individual err, tive events. The first category (Fig. 7B) is mostly composed of vesicular pumice clasts from rurtions dominated by explosions with a strong vertical component (Vulcanian events at S. 'יffì ̀ेe Hills, Lascar, and Kilian volcanoes, sub-Plinian and blasts events at Merapi and Mount St. HEicils volcanoes). The second category (Fig. 7C) is mostly composed of dense pumice clasts with diktytaxitic and intermediate, vesicular-diktytaxitic textures from dome collapse events (Soufrière Hills and Mt Pelée volcanoes) and lateral blast (Mt. Pelée volcano). Overall, number densities in natural samples are higher than those in experimental samples. Pumice clasts from vertical explosions have a wide OND range, spanning $10^{14}$ to $10^{17} \mathrm{~m}^{-3}$ and a VND range that clusters around $10^{15}$ to $10^{16} \mathrm{~m}^{-3}$ (Fig. 7B). As we assume no genetic link between oxides and $\mathrm{S} 2$ vesicles, we only 
report OND of diktytaxitic samples. The sample from the 1980 Mount St. Helens blast appears to be an outlier with low OND, which is likely due to the abundance of microlites that are too small to be detected (Cashman, 1988), and will not be considered further in our analysis. Figure 7C suggests that ONDs from dome collapse events are similar (within about one order of magnitude) to those from explosive events at the same volcano. The two samples from the 1929 block-and-ash flow at Mt Pelée are noteworthy. One sample is a pumice clast with $36 \mathrm{vol} \%$ vesicles that are rounded, which is a texture that is commonly found in most vesicular products of block-and-ash flows. The OND and VND of this sample are almost identical. The second sample is a (anse clast with $12 \mathrm{vol} \%$ vesicles that have a deflated texture with concave shapes, which is comm only interpreted as having resulted from outgassing and gas escape. For this sample, we consider $d$ th the collapsed vesicles were not directly linked genetically to oxides because coalescence $\mu^{1}{ }^{\top}$ cullapse modify number densities, and only reported the OND $\left(5 \times 10^{14} \mathrm{~m}^{-3}\right)$, which is close to th t or the more vesicular pumice $\left(1.3 \times 10^{15} \mathrm{~m}^{-}\right.$ $\left.{ }^{3}\right)$.

For some explosive events at Soufri * Hills, Kilian, and Merapi volcanoes, water content analyses have been used to retrieve pre- $t$ - nlosive values of porosity and pressure of the analyzed samples (Drignon et al., 2016; Colombic * t al., 2017; Burgisser et al., 2019). Although magma can rise in the conduit prior to a Vulc nian explosion in a step-wise fashion (Druitt et al., 2002; Jaquet et al., 2006; Clarke et al., 2007; : Manı et al., 2013), we tested here the simpler view that oxide microlite nucleate and grow betw en the noment magma leaves the reservoir and the moment it reaches its preexplosive position. Phasc quilibria experiments have constrained the main storage pressure to $\sim 130$ $\mathrm{MPa}$ at Soufrière Hills (Barclay et al., 1998) and to 350 MPa at Kilian (Martel et al., 2013). Estimating reservoir pressure at Merapi is a complex task because the magmas feeding the 2010 eruption were stored at multiple levels and mixed prior to their final ascent towards the surface (Costa et al., 2013; Nadeau et al., 2013; Preece et al., 2014; Erdmann et al., 2016; Widiyantoro et al., 2018). Here we follow Drignon et al. (2016) and assume a storage pressure of $300 \mathrm{MPa}$ so that it is slightly 
higher than the deepest conduit storage pressure of our samples while being compatible with the location of the main reservoir region (Widiyantoro et al., 2018). Figure 8 shows OND as a function of the pressure difference between the reservoir and the pre-explosive storage location in the conduit. There is no relationship between OND and reservoir-conduit pressure difference for the Merapi events. At Soufrière Hills and at Kilian (notwithstanding the limited data), these two parameters are positively correlated. The choice of the reservoir pressure does not influence these trends.

There is textural evidence that our VNDs track small bubbles nucleated during the explosion when magma leaves its pre-explosive location to be expelled into th atmosphere. At Soufrière Hills, Giachetti et al. (2010) and Burgisser et al. (2019) have shown t. at $\leqslant 1$ and L3 vesicles, which are mostly responsible for the VND values in non-diktytaxitic $\sin _{2}$ le, were formed in response to the decompression accompanying the Vulcanian explosions. M Tore than half (and often more than 80\%) of the oxides touch vesicles (Figs. 5 and 6A-B). In addition, wetiing angles between oxides and vesicle (Giachetti et al., 2010) are compatible with those hat indve been determined experimentally (Hurwitz and Navon, 1994). These lines of evidence aggest that oxides were nucleation sites for the synexplosive vesicles. Although our measuren. ents indicate vesicle-oxide connectivity of up to $90 \%$, in most cases only $15-40 \%$ of the vesirles ${ }^{*}$ ich oxides (Fig. 5), indicating large numbers of orphaned vesicles and highlighting the mo iy tı.nsformations affecting magma during ascent and subsequent evacuation. Pre-existing L2 asic es, for instance, are not expected to be in contact with oxides because they nucleatec he ire he oxide microlites. These crystal-rich magmas (the median vesiclefree crystal content is $45, \cdots \%$, Table $\mathrm{S} 1$ ) have limited interstitial space in which syn-explosive bubble growth and coalescence can occur, which changes bubble-oxide association. These transformations make it unlikely that the near linear relationship between VND and OND for the Merapi eruption (Fig. 7B) is fortuitous. We suggest instead that the VND is often 0.5 order of magnitude below the OND because some S1 syn-explosive bubbles underwent coalescence, thereby expanding the coarser syn-explosive population and lowering VNDs. This offset could even be an underestimate because 
ONDs represent minimum values. The more complex case of Soufrière Hills is discussed in section 4.2.1.

That VNDs are controlled by the sudden decompression accompanying conduit evacuation allows us to determine decompression rate at both Merapi and Soufrière Hills. When oxides are at least as numerous as vesicles in a given volume (Fig. 7A), Cluzel et al. (2008) have shown that the decompression rate needed to generate the observed VND can be calculated using the simplified nucleation model of Toramaru (2006). The 2010 Soufrière Hills samples were thus removed from this analysis because they have more vesicles than oxides (Fig. 7B), essures shown in Fig. 8 were calculated using the water solubility relationship of Liu et al. (200. ). T , circumvent the disadvantage that this relationship is not invertible while maintaining self- 20 - sic ency, we calculated the values of constants, $a$ and $b$, by fitting the relationship of Liu $t$ at (2005) with the following solubility relationship relating pressure in $\mathrm{MPa}, P$, to melt water ${ }^{\circ}$ ontent $\mathrm{in} \mathrm{wt} \%, C$ :

$$
C=a P^{b}
$$

The calculated values ( $a=0.3293$ and $b=0.5343$ 'or Soufrière Hills and $a=0.3054$ and $b=0.5402$ for Merapi) recover the relationship of $\operatorname{Li}_{1} f{ }^{9}$. (2005) over the pressure range of interest. Following Cluzel et al. (2008), we assumed a vate diffusivity of $10^{-11} \mathrm{~m}^{2} / \mathrm{s}$, a molecular volume of water in the

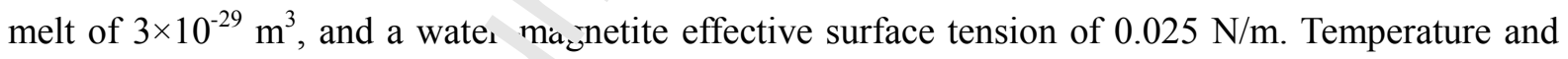
melt densities of $850^{\circ} \mathrm{C}$ ar $\lrcorner{ }^{1} 5 \mathrm{v} \mathrm{kg} / \mathrm{m}^{3}$ were used for Soufrière Hills (Barclay et al., 1998; Burgisser et al., 2010). Correspondı. ; values for Merapi were $930{ }^{\circ} \mathrm{C}$ and $2455 \mathrm{~kg} / \mathrm{m}^{3}$ (Costa et al., 2013; Erdmann et al., 2016). Figure 9 shows the resulting decompression rates alongside those at Kilian, which were obtained by Colombier et al. (2017) using a similar approach. The events at the three volcanoes yield similar rates of 3-30 MPa/s, regardless of sample position in the conduit. 


\section{Discussion}

\subsection{Experimental samples}

The three categories of experimental samples (Fig. 7A) are consistent with the conclusions of the respective experimental studies. Studies featuring more oxides than bubbles report agreement between VND and nucleation models (e.g., Toramaru, 1995; Toramaru, 2006) that are mainly controlled by supersaturation, water diffusivity, melt viscosity, and decompression rate (Cluzel et al., 2008; Shea et al., 2010). Studies featuring more bubbles than oxides $\mathrm{rt}_{\mathbf{r}}$ 'ort little agreement with such models (Gardner, 2007; Gardner and Denis, 2004). Among the $n_{c} \sim$ sle reasons proposed in those works for such mismatch, one is consistent with Fig. 7A. "Lriv) is relatively constant in MCR rhyolite, and probably reflects the number of sites for $n_{2}$.lea ion on magnetite (and the few ends of

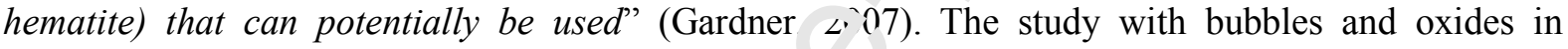
equivalent numbers (Burgisser and Gardner つい1) reports remarkably consistent VNDs between experiments having undergone a manual press . "e drop from 155 to $100 \mathrm{MPa}$ in $<1 \mathrm{~s}$. Our 3D analysis reveals that nearly all oxides in these s^mpiss have a bubble attached to them, and all bubbles are

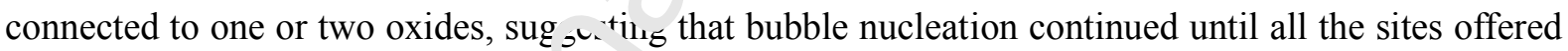
by the oxides were used. Revisitiı, `other experimental work addressing bubble growth (e.g., Cichy et al., 2011; Fiege and Cichy, 20,5) jy measuring ONDs might thus show that oxide-controlled bubble nucleation is more perva ${ }^{i t}:$ an currently thought.

These results suggest a simple, testable hypothesis to assess the likelihood of heterogeneous bubble nucleation. If, given a set of decompression conditions (melt composition, decompression rate, etc.) in a bubble-free, oxide-bearing melt, the OND is higher or equal to the VND predicted by heterogeneous nucleation models, the final number of nucleated bubbles will be consistent with model predictions. Conversely, if the decompression conditions are such that the VND predicted by heterogeneous nucleation models is higher than the OND, the final number of nucleated bubbles 
cannot be predicted accurately. Figure 7A hints that the OND could act as an upper limit to VND up to a certain degree of supersaturation above which nucleation is able to produce more bubbles than the number of available oxides. This has important implications for the interpretation of natural samples, which are explored in the next section.

One piece of evidence supporting that hypothesis can be found in the series of heating and decompression experiments from Pleše et al. (2018), Pleše et al. (2019a), and Pleše et al. (2019b). These studies report heterogeneous bubble nucleation in andesitic melts seeded with plagioclase, clinopyroxene, and oxides. Nucleation occurred first on plagioc se and/or clinopyroxene and, surprisingly, last on oxides. The melt-referenced OND of these sam ples ranges from $3.3 \times 10^{10}$ to $1.3 \times 10^{12} \mathrm{~m}^{-3}$ assuming a crystal content of $30 \mathrm{vol} \%$ for all $\mathrm{s} \mathrm{n}_{\perp_{1}}$ ler (Pleše et al., 2018). The VND is not reported in the heating experiments of Pleše et al. (20 8) t cause of segmentation issues (P. Pleše, pers. comm. 2019). Using the reported bubble and samule volumes and assuming an average bubble size of 10 to $100 \mu \mathrm{m}$ based on the $\mu \mathrm{CT}$ images, vur rough estimate of the melt-referenced VND is $3 \times 10^{11}-7 \times 10^{15} \mathrm{~m}^{-3}$. Using the reported bulk $/ \mathrm{ND}$ in pure melt regions and assuming an average porosity of $10-20 \mathrm{vol} \%$ based on the $\mu \mathrm{CT}$ เ nages, our rough estimate of the melt-referenced VND in the decompression experiments of $P^{1} \sim$ še ${ }^{+}$al. (2019a) is $8 \times 10^{12}-8 \times 10^{14} \mathrm{~m}^{-3}$. In both series, every sample has a VND that is alw vs larger than its OND, suggesting that oxides were present in insufficient numbers to provic $\mathrm{m}$ onomineral nucleation sites for the bubbles. Nucleation was thus prone to occur on the the $r$ lases that were present. This interpretation does not undermine the finding that plagioclase with rough surfaces have better nucleation properties than previously envisioned (Pleše et al., 2018). Instead, it provides an alternate explanation of why oxides were the last occupied nucleation sites in both experimental series.

\subsection{Natural cases}

Fe-Ti oxides are subject to fast re-equilibration during decompression because of cooling, 
changes in redox state and melt water loss (e.g., Andersen and Lindsley, 1988; Venezky and Rutherford, 1999; Devine et al., 2003; Ghiorso and Evans, 2008). Although the decompression threshold for bubble nucleation is lower for magnetite than, for instance, hematite (Cluzel et al., 2008), the end-members of the solid solution are not separated in our data. This warrants further investigation by using, for instance, element mapping (Muir et al., 2012; Drignon et al., 2016) instead of SEM imaging to distinguish between the ONDs of hematite, ilmenite, and magnetite. For simplicity, in the following discussion, we ignore that several bubbles can nucleate on the same crystal, increasing the final VND by at most 0.5 order of magn ude (Gardner and Denis, 2004; Edmonds et al., 2015), and that other phases can cause heterogener us $\mathrm{n}_{1}$ icleation, which also increases the VND (Hurwitz and Navon, 1994; Pleše et al., 2018). V'e al o keep in mind that ONDs are minimum values because our analysis cannot identify nanr in s tiat are $<380 \mathrm{~nm}$.

Despite these limitations, the observation that the VNDs at Soufrière Hills, Kilian, and Merapi result from a narrow range of high decompressic " raıs regardless of pre-explosive storage pressure (Fig. 9) is compatible with the $0.1-10 \mathrm{MPa}^{\prime}$ propagation rate of the fragmentation front given by conduit flow model simulations of short-1 ed Vulcanian eruptions at Soufrière Hills (Mason et al., 2006). The fragmentation front that (is upts the magma column and feeds the explosion is accompanied by a decompressin , fru.tt that either is collocated with that fragmentation front, or propagates downward into the nart of the conduit that is still intact (Burgisser et al., 2011). Combined with the presence of $n \mathbf{x p}^{1}$ sive vesicles and high levels of oxide-vesicle connectivity, Fig. 9 suggests that such decor..., ession front is responsible for syn-explosive bubble nucleation in these Vulcanian and sub-Plinian events. The new bubbles and the associated expansion favor fragmentation, regardless of whether decompression is collocated with fragmentation. Further interpretation of these rates is not easy because the conversion from decompression rate to fragmentation speed depends on the fragmentation mechanism (Toramaru, 2006; Burgisser et al., 2011; Miwa and Geshi, 2012) and on the magma physical properties (Alatorre-Ibargüengoitia et al., 2011; Richard et al., 2013). This result, 
however, allows us to posit that a minimum OND is needed in the conduit for the decompression front to nucleate bubbles. Conversely, if oxides are too sparse, the front does not create enough bubbles and magma expansion stops, which is likely to end explosive conduit evacuation. The first-order consequence of this conjecture is that conditions for nucleation were adverse at great depths at Soufrière Hills ( $<50 \mathrm{MPa}$ above the reservoir, Fig. 8) but were propitious at all depths at Merapi. This partly explains the much deeper evacuation at Merapi. In the next section, we bring together pieces of evidence that support the hypothesis that transition from effusive to explosive eruptions is controlled by the absence or presence of oxide microlites in the conduit, respec 'vely.

\subsubsection{Oxides as controls of the effusive-explosive transition}

Oxide equilibria conditions are much better known tha $1 t_{1}-$ nucleation behavior in reaction to decompression. If a mineral phase has reached saturation whi ther precipitation occurs by nucleation or by growth depends on the instantaneous level of $d$ : quilibrium (e.g., Hammer, 2008; Andrews and Befus, 2020). When ascent conditions are smo th (1.e. devoid of stalling or acceleration), larger disequilibrium levels are easier to achieve $a_{\imath}$.hallow depth. It is thus possible to relate the largest microlites to the deepest levels of nucle tion, whereas more numerous, smaller microlites and nanolites appear at shallow levels ( $M_{-}^{1}$ ni. $^{\prime}$, al., 2011).

The Toramaru et al. (20n8). יucleation model relates OND to ascent rate as a function of the initial conditions (pressure mo L__lt water content) for microlite nucleation. This model was used by Murch and Cole (2019) u - the Soufrière Hills plagioclase microlite with a modest level of success. Their results highlighted that model validity is restricted to nucleation-dominated decompression conditions, which are unlikely to be fulfilled in the case of lava dome samples that have undergone complex ascent paths with stalling and/or accelerations. With this limitation in mind, in the next part of this section, we determine the most likely depth of nucleation-dominated appearance of oxides at both Soufrière Hills and Merapi, and then use the model of Toramaru et al. (2008) to deduce ascent rates from our ONDs. 
The ONDs at Merapi volcano cluster around $10^{16}-10^{17} \mathrm{~m}^{-3}$, regardless of the conduit-reservoir pressure (Fig. 8). This suggests that oxide microlites nucleated early in the ascent process, which is expected because oxide phenocrysts were present in the reservoir (Costa et al., 2013; Preece et al., 2014; Erdmann et al., 2016). The positive relationship between OND and reservoir-conduit pressure difference at Soufrière Hills suggests instead that oxide microlite nucleated continuously during ascent. This is consistent with nucleation of oxide, clinopyroxene, and plagioclase during experimental decompression of magmas having the composition of the most evolved groundmass of Soufrière Hills dome products (Couch et al., 2003).

The derivative, $\mathrm{d} \phi / \mathrm{d} P$, of the equilibrium crystal volume frac tion $\phi$, with respect to pressure, $P$, is a measure of how much a parcel of magma is prone to nucl sai $\curvearrowright n$. To take feldspar crystallization in the Soufrière Hills magma as a proof of principle, rhyoli e-M ZLTS 1.2 (Gualda et al., 2012, detailed initial conditions are given in Supplementary Text s $^{1}$, predicts a power law increase of plagioclase volume fraction with decreasing pressure that stai $\sim$ at $\sim 10 \mathrm{MPa}$. This is compatible with the inference that the most abundant plagioclase microlite .ppear at 6-10 MPa (Clarke et al., 2007; Murch and Cole, 2019). Here we use $\mathrm{d} \phi / \mathrm{d} P$ to determin - the origin of the most abundant oxides at both Soufrière Hills and Merapi.

The magmas feeding th 2010 Merapi eruption were stored at various levels before being assembled and erupted. We ..`w . . fine the single storage pressure used to build Fig. 8 by considering the three starting conci ions proposed by Erdmann et al. (2016) for the rhyolite-MELTS decompression. The deep reservoir and the recharge magma decompressions are thus starting at 200 MPa (Supplementary Text S4). Shallow reservoir decompression starts at $100 \mathrm{MPa}$, even if preexplosive conduit storage pressures larger than those values were reported by Drignon et al. (2016) and in Fig. 8. The initial conditions of the rhyolite-MELTS decompression of Soufrière Hills magma are the same as for Fig. 8 (Supplementary Text S4).

Figure 10 shows the volume fraction of crystals produced/dissolved per unit of pressure as a 
function of pressure for Fe-Ti oxide phases in the Soufrière Hills and Merapi melts. It suggests that the transition from (no) growth to nucleation occurs in the Soufrière Hills conduit at $\sim 20 \mathrm{MPa}$ for magnetite and $\sim 50 \mathrm{MPa}$ for ilmenite. Magnetite nucleation at Merapi is expected to occur at $\sim 10$, $\sim 100$, or $\sim 200 \mathrm{MPa}$, depending on the host magma. These calculated stability domains are compatible with the observed oxide compositions at both volcanoes (Supplementary Text S4; Devine et al., 2003; Costa et al., 2013). The resulting nucleation pressures can thus be used as an input into the Toramaru et al. (2008) decompression meter to determine ascent rates.

We calculated ascent rates for each sample with the Toramas. et al. (2008) model using the OND of that sample and the nucleation pressures and correspor ing melt water contents deduced from Fig. 10 (Supplementary Text S5). Figure 11 shows the fru ruf ncy distribution of ascent rates at both Soufrière Hills and Merapi. Overall, Fig. 11 sugges $1 s$ th ${ }^{*}:$ ascent rates on the order of $0.005-20$ $\mathrm{m} / \mathrm{s}$ were necessary to produce the observed ONDs. A cinnilarly wide range of ascent rates is obtained if, instead of considering one OND per sample, c"e uses the typical spread of ONDs in the microlite size range found in the eruptive products ${ }^{\top}$ igs. S5-7). The main control of these rates is the nucleation depth, which is particularly not - eable in the case of Merapi (Fig. 11B) owing to the very different origin depths between the three $r$ pted magmas.

Keeping in mind that our es imates are average rates between the nucleation depth and the preexplosive location, whereas $m_{a_{c}}{ }^{-n d}$ ascent is a dynamic process, the rates of Fig. 11 greatly overlap with the critical ascent $\mathrm{ra}^{\sim}$ lange of $0.005-0.25 \mathrm{~m} / \mathrm{s}$ for the effusive-explosive transition compiled by Cassidy et al. (2018) who included Soufrière Hills in their compilation. This overlap is not a consequence of shared methodologies because the ascent rates in Cassidy et al. (2018) were estimated using methods that are independent from the oxide microlite decompression meter of Toramaru et al. (2008). Effusive activity is thus far more likely to occur at rates $<0.005 \mathrm{~m} / \mathrm{s}$, which coincide with rates at which oxide nucleation is unlikely to happen in the conduit. A corollary prediction is that lava dome eruptions have small ONDs at depth. 
A robust test of the hypothesis that the effusive-explosive transition is controlled by the distribution of OND in the conduit would be to measure the OND of a deep sample of an effusive eruption. Unfortunately, as shown by Fig. 7C, lava dome samples have all reached near-surface conditions where numerous oxides can nucleate in response to cooling, making the formal verification of this hypothesis difficult. There is, however, indirect experimental evidence that oxides do not nucleate at depth during effusive eruptions. Considering that the Soufrière Hills magma contains oxide phenocrysts inherited from the reservoir (e.g., Devine et al., 2003), Martel and Schmidt (2003) have shown that slow decompression from reservoir level to 5( MPa in more than 5-15 days $(<0.003-0.009 \mathrm{~m} / \mathrm{s})$ causes oxide crystallization to occur by grow $\mathrm{h}$ in tead of nucleation. A conduit filled with slowly rising magma will thus contain the oxide ca go it herited from the reservoir, which is not numerous enough $\left(\mathrm{OND}<10^{11} \mathrm{~m}^{-3}\right.$, Figs. $\left.\mathrm{S} 5-7\right)$ to an as systematic bubble nucleation sites. Even if other Fe-bearing minerals are present, only lo ge $>20 \mathrm{MPa}$ ) pressure fluctuations could trigger heterogeneous nucleation in such a conduit $L_{i}, \mathrm{or}$ the other hand, the magma rises fast enough to reach the range of ascent rates at which ans cional and pulsatory effusive and explosive activities are likely, the local decompression rates re also sufficient to yield the high ONDs observed in the conduit. Enough new oxides will be adrec to the crystal cargo for the magma to nucleate bubbles when pressure fluctuations are as $\mathrm{m}_{\mathrm{\iota}}{ }^{11}$ as $5-20 \mathrm{MPa} / \mathrm{s}$.

It is thus not accidentai that ne critical ascent rates at which transitional effusive and explosive activities occur overla, tho $a^{+}$which new oxides are nucleated in the conduit. Oxide microlites are a primer for explosive beh. *or (Cáceres et al., 2020) because they considerably lower the threshold of pressure changes needed for heterogeneous bubble nucleation (Shea et al., 2010). This strongly supports the conjecture that the OND has to be above a given threshold for the decompression front (section 4.2) to nucleate bubbles. Conversely, it also suggests that if insufficient amounts of oxides are present in a given part of the conduit, no bubbles will nucleate when the decompression front arrives. The resulting lack of bubble-rich magma ready to expand (Burgisser et al., 2011) stops the explosion 
from propagating downward, aborting it. One exception to the latter scenario is if the burden evacuated is large enough to foster homogeneous nucleation and rapid gas expansion, such as in the case of a cryptodome suddenly exposed to atmospheric pressure (e.g., Mount St. Helens in 1980).

Overall, this reasoning gives a new meaning to the critical range of ascent rates observed by Cassidy et al. (2018); the critical range is defined by the rates at which oxides nucleate in the conduit. We thus propose that the presence of oxides at depth is a major control of the effusive to explosive transition.

Here we explore two consequences of the posited relationship $\iota$ tween OND and explosivity. First, the 2010 Soufrière Hills explosion features near constant $V_{1}{ }^{n}$, regardless of the OND. This could be partly due to heterogeneous nucleation on other phr es such as pyroxenes, or to the presence of nanolites. This is also reminiscent of the experim tts vith VND $>$ OND, in which a similar saturation density occurs (Fig. 7A). Leaving nano'ıte, aside, this suggests that the decompression magnitude was too high for the number of ox: '`s ${ }^{\text {" }}$ esent and that bubble nucleation was more erratic because it depended on a poorly understood . nd spatially heterogeneous combination of available nucleation sites, decompression mar, ituc?, and decompression rate (Gardner, 2007). Our interpretation of the Pleše et al. $\left(20^{1} 0\right.$, experiments suggests that syn-explosive bubbles nucleated on the other minerals because oxidt. were not numerous enough to provide monomineral nucleation sites. This implies that oxides $w: r r$ the last occupied nucleation sites in that Vulcanian event.

The second consequ nce bears on the interpretation of older eruptions for which no observation such as dome growth rate is available but for which pre-eruptive conditions are known. This is the case of the 9.4 ka BP Vulcanian eruption of Kilian volcano (Martel et al., 2013; Colombier et al., 2017; Colombier et al., submitted). Its trachytic composition differs strongly from the more calcalkaline magmas of Soufrière Hills and Merapi. As a result, oxides nucleate at 20-50 MPa (Fig. 12A). Figure 12B shows that the measured ONDs resulted from ascent rates lying in the $0.01-1 \mathrm{~m} / \mathrm{s}$ range, which is within that of the critical ascent rates compiled by Cassidy et al. (2018). It also implies that 
below $\sim 7 \times 10^{-3} \mathrm{~m} / \mathrm{s}$ no magnetite microlite would crystallize in the conduit before reaching the cooling dome, making this ascent rate the minimum threshold value for the transition between effusive and explosive behavior.

\section{Conclusions}

We used new, re-analyzed, and published data to build a compilation of oxide number densities (ONDs) and vesicle number densities (VNDs) of samples from explosive and effusive products at five volcanoes, totaling 76 new determinations and 31 determinations fro 1 the literature. Natural samples were from products of Vulcanian explosions at Soufrière Hills, Las ar, and Kilian volcanoes, of laterally directed blasts at Mt Pelée, Mount St. Helens, and M tapi volcanoes, of a sub-Plinian event at Merapi volcano, and of lava dome effusion with inte mi ent collapse at Soufrière Hills and Mt Pelée volcanoes.

Natural samples were separated into twrn g, ups according to the dominant texture present in the samples from individual eruptive events. 1 e first group is mostly composed of vesicular pumice clasts from eruptions dominated by explnsiv. $\varsigma$ with a strong vertical component (Vulcanian events at Soufrière Hills, Lascar, and Kilian r vananes, sub-Plinian and blasts events at Merapi and Mount St. Helens volcanoes). Samples frol. that category are either distributed within $0.5 \log$ unit of the 1:1 trend between VND and OND . hat spans from $10^{15}$ to $10^{17} \mathrm{~m}^{-3}$, or have a constant VND of $10^{16}-10^{16.5}$ $\mathrm{m}^{-3}$ regardless of ONL. A : $\mathrm{ge}$ proportion of oxides $(55-100 \%)$ touch vesicles whereas a more variable proportion of vesicles (16-72\%) are in contact with oxides.

The second group is mostly composed of dense pumice clasts with diktytaxitic and intermediate, vesicular-diktytaxitic textures from dome collapse event (Soufrière Hills and Mt Pelée volcanoes) and lateral blast (Mt. Pelée volcano). Samples from that category have ONDs in the same broad range as their more explosive counterparts. Their VNDs were not measured because their diktytaxitic textures suggest that vesicles are gaps between crystals with no genetic link to oxides. 
We compiled new and published data of ONDs and VNDs of five series of experimental decompression of rhyolitic and phonolitic melts, totaling 3 new samples and 46 samples from the literature. Number density data suggest that samples can be divided into three categories: those featuring more oxides than bubbles, those with more bubbles than oxides, and those with bubbles and oxides in equivalent numbers. In this last category, experimental bubbles touch, on average, 1.6-2.2 oxides (i.e. most bubbles are in contact with two oxides whereas the other bubbles are either isolated or touching one oxide) while $64-88 \%$ of the oxides are in contact with bubbles. These high levels of connectivity suggest that the role of oxides in controlling bubble $\mathrm{r}$ irleation in these decompression experiments has been underestimated. When oxides are at least is n $\mathrm{h}$ nerous as vesicles in a given volume (i.e. when OND>VND), heterogeneous nucleation mc tels 'e.g., Toramaru, 1995; Toramaru, 2006) are able to reproduce the nucleation density of ves an a function of supersaturation, water diffusivity, melt viscosity, and decompression rate. Wr in c.ides are less abundant than nucleated vesicles at the final pressure (i.e. when $\mathrm{ONC}<\mathrm{NI}$ ), these models are unable to reproduce experimental data. In that case, comparati ely nuch larger supersaturation pressures are needed to achieve the same VND as when OND>V. T'.

Building on the textural evidence $t^{\prime}$ at VNDs track small bubbles nucleated during conduit evacuation, we calculated the $d c^{-} \mathrm{m}_{\mathrm{L}_{\mathrm{r}}}$ ression rates responsible for the VNDs at both Merapi and Soufrière Hills. They fall wi.'-in tie same range as those at Kilian volcano (3-30 MPa/s), and are compatible with the $\mathrm{fra}_{i}{ }^{-} \mathrm{mc}$ 'tat on front propagation rates given by conduit flow model simulations at Soufrière Hills (Mason e . ..., 2006). Combined with the presence of syn-explosive vesicles and high levels of oxide-vesicle connectivity, this suggests that the decompression front accompanying these Vulcanian and sub-Plinian explosions is responsible for syn-explosive bubble nucleation. This result allows us to posit that a minimum OND is needed in the conduit for the decompression front to nucleate bubbles. Conversely, if there are not enough oxides, the front does not create enough bubbles and magma expansion stops, bringing explosive conduit evacuation to an end. 
We used rhyolite-MELTS and the Toramaru et al. (2008) nucleation model to calculate the average ascent rates necessary to yield the observed ONDs at Soufrière Hills and Merapi volcanoes. The resulting rates, $0.005-20 \mathrm{~m} / \mathrm{s}$, greatly overlap with the range of critical ascent rate inferred for the effusive-explosive transition (Cassidy et al., 2018). This overlap is not fortuitous; oxides nucleated in the conduit have been proposed to be a primer for explosive behavior (Cáceres et al., 2020) because they require a very small pressure drop for heterogeneous bubble nucleation to occur. Our results thus suggest that a conduit filled with slowly rising magma will only contain the oxide cargo inherited from the reservoir. In the cases included in this study, this c. rso was not numerous enough $\left(\mathrm{OND}<10^{11} \mathrm{~m}^{-3}\right)$ to act as systematic bubble nucleation sites. Ev $\mathrm{n}$ i1 ther Fe-bearing minerals are present, only large ( $>20 \mathrm{MPa})$ pressure fluctuations could trig conduit. If, on the other hand, the magma rises fast enr us $w$ reach rates at which the effusiveexplosive transition is likely, our results show that the lo al a compression rates are also sufficient to yield the high ONDs observed in the conduit. S $\mathrm{u}_{1}{ }^{r} \cdot \mathrm{ci}$, nt quantities of oxide microlites have then crystallized for the magma to nucleate bubb $2 \mathrm{~s} v$ nen small pressure fluctuations occur.

We thus propose that the presence of oxide at depth is a major control of the effusive to explosive transition. The OND has $\mathfrak{n} \mathrm{t}$, bove a given threshold so that the decompression front accompanying magma disruptior and vacuation nucleates bubbles. Conversely, if, in a given part of the conduit, insufficient oxidt. are present, then bubbles do not nucleate even when the fragmentation front arrives. Applied ' $\cdots$ r r ider eruption of Kilian, our results suggest that $\sim 7 \times 10^{-3} \mathrm{~m} / \mathrm{s}$ is the minimum threshold valu $i \dot{i}$ ascent rate for the transition between effusive and explosive behavior at that volcano.

\section{Acknowledgments}

We thank S. Moune for providing the Lascar samples and D. Picard for the textural analysis of samples from Soufrière Hills, Lascar, and Mt. Pelée. Thorough comments from two anonymous 
reviewers helped improve the manuscript readability and we thank K. Russell for his impeccable editorial handling. This study was partially funded by a grant from Labex OSUG@2020 (Investissements d'avenir - ANR10 LABX56), grant ANR-19-CE31-0007, and grant 202844 from the European Research Council under the European FP7. The VOLTAIRE project (ANR-10-LABX-10001) funded by ANR through the PIA (Programme Investissement d'Avenir) are gratefully acknowledged for the measurements performed at ISTO. 


\section{References}

Adams, N.K., Houghton, B.F., Hildreth, W., 2006. Abrupt transitions during sustained explosive eruptions: examples from the 1912 eruption of Novarupta, Alaska. Bull. Volcanol. 69, 189206. https://doi.org/10.1007/s00445-006-0067-4

Alatorre-Ibargüengoitia, M.A., Scheu, B., Dingwell, D.B., 2011. Influence of the fragmentation process on the dynamics of Vulcanian eruptions: An experimental approach. Earth Planet. Sci. Lett. 302, 51-59. https://doi.org/10.1016/j.epsl.2010.11.045

Andersen, D.J., Lindsley, D.H., 1988. Internally consistent solution models for Fe-Mg-Mn-Ti oxides; Fe-Ti oxides. Am. Mineral. 73, 714-726.

Andrews, B.J., Befus, K.S., 2020. Supersaturation Nucleation and Growth of Plagioclase: a numerical model of decompression-induced crystallization. Contrib. Mineral. Petrol. 175, 23. https://doi.org/10.1007/s00410-020-1660-9

Barclay, J., Rutherford, M.J., Carroll, M.R., Murphy, M.D., Devine, , )., Gardner, J., Sparks, R.S.J., 1998. Experimental phase equilibria constraints on pre-erur.--re surage conditions of the Soufriere Hills magma. Geophys. Res. Lett. 25, 3437-344C

Burgisser, A., Arbaret, L., Druitt, T.H., Giachetti, T., 2011. Pre- - $x_{F}^{\prime}$ 'osive conduit conditions of the 1997 Vulcanian explosions at Soufrière Hills Volcans, ${ }_{1}$ on serrat: II. Overpressure and depth distributions. J. Volcanol. Geotherm. Res. 199, 193-2i'5.

Burgisser, A., Bechon, T., Chevalier, L., Collombet, M., f rba st, L., Forien, M., 2019. Conduit processes during the February 11, 2010 Vulcanian _-.stion of Soufrière Hills, Montserrat. J. Volcanol. Geotherm. Res. 373, 23-35. https:///oi.org/10.1016/j.jvolgeores.2019.01.020

Burgisser, A., Chevalier, L., Gardner, J.E., Castro, J M., . 017. The percolation threshold and permeability evolution of ascending magr as. Larth Planet. Sci. Lett. 470, 37-47. https://doi.org/10.1016/j.epsl.2017.0/.0 33

Burgisser, A., Gardner, J.E., 2004. Experime tr. constraints on degassing and permeability in volcanic conduit flow. Bull. Volcanol. 6, 42-56. https://doi.org/10.1007/s00445-004-0359-5

Burgisser, A., Poussineau, S., Arbaret, L., Lruitt, T.H., Giachetti, T., Bourdier, J.-L., 2010. Preexplosive conduit conditions of in. 1497 Vulcanian explosions at Soufrière Hills Volcano, Montserrat: I. Pressure and vesic lo ity distributions. J. Volcanol. Geotherm. Res. 194, $27-$ 41. https://doi.org/10.1016/i ivo, coores.2010.04.008

Cáceres, F., Wadsworth, F.B., Scl eu, ‥, Colombier, M., Madonna, C., Cimarelli, C., Hess, K.-U., Kaliwoda, M., Ruthensí int: B., Dingwell, D.B., 2020. Can nanolites enhance eruption explosivity? Geology. http. .//doi.org/10.1130/G47317.1

Cashman, K.V., 1988. Cry 'añ 'iaulon of Mount St. Helens 1980-1986 dacite: A quantitative textural approach. Bull. Vo' an i. 50, 194-209.

Cassidy, M., Manga, M., L shman, K., Bachmann, O., 2018. Controls on explosive-effusive volcanic eruption styles. $\Gamma^{\text {nt }}$. Commun. 9, 2839. https://doi.org/10.1038/s41467-018-05293-3

Castro, J.M., Burgisser, A., Schipper, C.I., Mancini, S., 2012. Mechanisms of bubble coalescence in silicic magmas. Bull. Volcanol. 74, 2339-2352. https://doi.org/10.1007/s00445-012-0666-1

Cichy, S.B., Botcharnikov, R.E., Holtz, F., Behrens, H., 2011. Vesiculation and Microlite Crystallization Induced by Decompression: a Case Study of the 1991-1995 Mt Unzen Eruption (Japan). J. Petrol. 52, 1469-1492. https://doi.org/10.1093/petrology/egq072

Clarke, A.B., Stephens, S., Teasdale, R., Sparks, R.S.J., Diller, K., 2007. Petrologic constraints on the decompression history of magma prior to Vulcanian explosions at the Soufrière Hills volcano, Montserrat. J. Volcanol. Geotherm. Res. 161, 261-274. https://doi.org/10.1016/j.jvolgeores.2006.11.007

Cluzel, N., Laporte, D., Provost, A., Kannewischer, I., 2008. Kinetics of heterogeneous bubble nucleation in rhyolitic melts: implications for the number density of bubbles in volcanic 
conduits and for pumice textures. Contrib. Mineral. Petrol. 156, 745-763. https://doi.org/10.1007/s00410-008-0313-1

Colombier, M., Gurioli, L., H. Druitt, T., Shea, T., Boivin, P., Miallier, D., Cluzel, N., 2017. Textural evolution of magma during the 9.4-ka trachytic explosive eruption at Kilian Volcano, Chaîne des Puys, France. Bull. Volcanol. 79. https://doi.org/10.1007/s00445-017-1099-7

Colombier, M., Shea, T., Burgisser, A., Druitt, T.H., Gurioli, L., Mueller, D., Cáceres, F., Hess, K.U., Dingwell, D.B., 2020. Rheological change and degassing during a trachytic Vulcanian eruption at Kilian volcano, Chaîne des Puys, France. Bull. Volcanol.

Costa, F., Andreastuti, S., Bouvet de Maisonneuve, C., Pallister, J.S., 2013. Petrological insights into the storage conditions, and magmatic processes that yielded the centennial 2010 Merapi explosive eruption. J. Volcanol. Geotherm. Res. 261, 209-235. https://doi.org/10.1016/j.jvolgeores.2012.12.025

Couch, S., Sparks, R.S.J., Carroll, M.R., 2003. The kinetics of degassing-induced crystallization at Soufrière Hills volcano, Montserrat. J. Petrol. 44, 1477-1502.

Degruyter, W., Burgisser, A., Bachmann, O., Malaspinas, O., 2010. vnchrotron X-ray microtomography and lattice Boltzmann simulations of gas flow through volcanic pumices. Geospheres 6, 470-481.

Devine, J.D., Rutherford, M.J., Norton, G.E., Young, S.R., 2003 inferred from geochemistry of Fe-Ti oxides in andesitic mag na, Soufrière Hills volcano, Montserrat, W.I. J. Petrol. 44, 1375-1400.

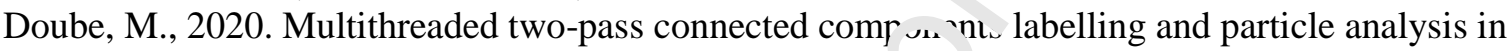
ImageJ. bioRxiv 2020.02.28.969139. https://doi.c. r/11 .1101/2020.02.28.969139

Drignon, M.J., Bechon, T., Arbaret, L., Burgisser, A., Kc nor 'yski, J.-C., Caroline, M., Hayden, M., Yaputra, R., 2016. Preexplosive conduit con $\lrcorner 1 t^{\circ}$ ' 'ns during the 2010 eruption of Merapi volcano (Java, Indonesia). Geophys. Res. '.e.' 4', 11,595-11,602. https://doi.org/10.1002/2016GL071152

Druitt, T.H., Young, S.R., Baptie, B., Bonac onn ،, C., Calder, E.S., Clarke, A.B., Cole, P.D., Harford, C.L., Herd, R.A., Luckett, R., Ryan, G., Voight, B., 2002. Episodes of cyclic Vulcanian explosive activity with fountain c. llapse at Soufrière Hills Volcano, Montserrat. Geol. Soc. Lond. Mem. 21, 281-306. https" "'do1. rg/10.1144/GSL.MEM.2002.021.01.13

Edmonds, M., Brett, A., Herd, R.A., Hı.n ph ıeys, M.C.S., Woods, A., 2015. Magnetite-bubble aggregates at mixing interfa $e_{s}$ i $\eta$ andesite magma bodies. Geol. Soc. Lond. Spec. Publ. 410, 95-121. https://doi.org/1C 1, 14/SP410.7

Erdmann, S., Martel, C., Pichavan., M., Bourdier, J.-L., Champallier, R., Komorowski, J.-C., Cholik, N., 2016. Constraints fron. Phase Equilibrium Experiments on Pre-eruptive Storage Conditions in Mixed Man a Systems: a Case Study on Crystal-rich Basaltic Andesites from Mount Merapi Inc ones a. J. Petrol. 57, 535-560. https://doi.org/10.1093/petrology/egw019

Fiege, A., Cichy, S.B., $2 u^{15}$. Experimental constraints on bubble formation and growth during magma ascent: A review. A n. Mineral. 100, 2426-2442. https://doi.org/10.2138/am-2015-5296

Gardner, J.E., 2007. Heterogeneous bubble nucleation in highly viscous silicate melts during instantaneous decompression from high pressure. Chem. Geol. 236, 1-12.

Gardner, J.E., Denis, M.-H., 2004. Heterogeneous bubble nucleation on Fe-Ti oxide crystals in highsilica rhyolitic melts. Geochim. Cosmochim. Acta 68, 3587-3597.

Ghiorso, M.S., Evans, B.W., 2008. Thermodynamics of Rhombohedral Oxide Solid Solutions and a Revision of the FE-TI Two-Oxide Geothermometer and Oxygen-Barometer. Am. J. Sci. 308, 957-1039. https://doi.org/10.2475/09.2008.01

Giachetti, T., Burgisser, A., Arbaret, L., Druitt, T.H., Kelfoun, K., 2011. Quantitative textural analysis of Vulcanian pyroclasts (Montserrat) using multi-scale X-ray computed microtomography: comparison with results from 2D image analysis. Bull. Volcanol. 73, 1295-1309. https://doi.org/10.1007/s00445-011-0472-1 
Giachetti, T., Druitt, T.H., Burgisser, A., Arbaret, L., Galven, C., 2010. Bubble nucleation, growth and coalescence during the 1997 Vulcanian explosions of Soufrière Hills Volcano, Montserrat. J. Volcanol. Geotherm. Res. 193, 215-231.

Gualda, G.A.R., Anderson, A.T., 2007. Magnetite scavenging and the buoyancy of bubbles in magmas. Part 1: Discovery of a pre-eruptive bubble in Bishop rhyolite. Contrib. Mineral. Petrol. 153, 733-742. https://doi.org/10.1007/s00410-006-0173-5

Gualda, G.A.R., Ghiorso, M.S., Lemons, R.V., Carley, T.L., 2012. Rhyolite-MELTS: a Modified Calibration of MELTS Optimized for Silica-rich, Fluid-bearing Magmatic Systems. J. Petrol. 53, 875-890. https://doi.org/10.1093/petrology/egr080

Hammer, J., 2008. Experimental Studies of the Kinetics and energetics of Magma Crystallization. Rev. Mineral. Geochem. 69, 9-59.

Hurwitz, S., Navon, O., 1994. Bubble nucleation in rhyolitic melts: Experiments at high pressure, temperature, and water content. Earth Planet. Sci. Lett. 122, 267-280.

Jaquet, O., Sparks, R.S.J., Carniel, R., 2006. Magma memory recorded by statistics of volcanic explosions at the Soufrière Hills volcano, Montserrat. pp. 17 - 184 TY2-KW-0.

Knipping, J.L., Bilenker, L.D., Simon, A.C., Reich, M., Barra, F., Dedı' 's, A.P., Lundstrom, C., Bindeman, I., Munizaga, R., 2015. Giant Kiruna-type depc its i orm by efficient flotation of

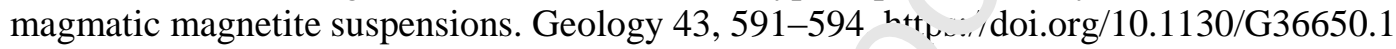

Komorowski, J.-C., Jenkins, S., Baxter, P.J., Picquout, A., Lavi rne, ' ., Charbonnier, S., Gertisser, R., Preece, K., Cholik, N.,. Budi-Santoso, A., Surono, -, 01 s. Paroxysmal dome explosion during the Merapi 2010 eruption: Processes and fa in ruationships of associated high-energy pyroclastic density currents. J. Volcanol. Geothel.' R' s. 261, 260-294.

Laumonier, M., Arbaret, L., Burgisser, A., Champallier, F.., ' $\iota^{1} 11$. Porosity redistribution enhanced by strain localization in crystal-rich magmas. G $\mathrm{o}^{\prime}$ joy $39,715-718$. https://doi.org/10.1130/G31803.1

Lensky, N.G., Navon, O., Lyakhovsky, V., $20^{\sim}$ - b. hble growth during decompression of magma: experimental and theoretical investi atir n. J. Volcanol. Geotherm. Res. 129, 7-22.

Liu, Y., Zhang, Y., Behrens, H., 2005. Solubilı.' of H2O in rhyolitic melts at low pressures and a new empirical model for mixed H2O- $\bigcirc 2$ solubility in rhyolitic melts. J. Volcanol. Geotherm. Res. 143, 219-235.

Loughlin, S.C., Calder, E.S., Clarke, A., Y o e, P.D., Luckett, R., Mangan, M.T., Pyle, D.M., Sparks, R.S.J., Voight, B., Watts, R s., ? v22. Pyroclastic flows and surges generated by the 25 June 1997 dome collapse, Souf it. Hills Volcano, Montserrat. Geol. Soc. Lond. Mem. 21, 191209. https://doi.org/10.11 $1 /$ GSL.MEM.2002.021.01.09

Loughlin, S.C., Luckett, R., Rvan, T., Christopher, T., Hards, V., De Angelis, S., Jones, L., Strutt, M., 2010. An overview of $\mathrm{la}{ }^{m}$ dome evolution, dome collapse and cyclicity at Soufrière Hills Volcano, Montsen at, 2 05-2007. Geophys. Res. Lett. 37.

Mann, C.P., Wallace, P.J. Siı, J., 2013. Phenocryst-hosted melt inclusions record stalling of magma during ascent in the sonduit and upper magma reservoir prior to vulcanian explosions, Soufrière Hills volcano, Montserrat, West Indies. Bull. Volcanol. 75, 687. https://doi.org/10.1007/s00445-013-0687-4

Martel, C., 2012. Eruption Dynamics Inferred from Microlite Crystallization Experiments: Application to Plinian and Dome-forming Eruptions of Mt. Pelée (Martinique, Lesser Antilles). J. Petrol. 53, 699-725.

Martel, C., Bourdier, J.-L., Pichavant, M., Traineau, H., 2000. Textures, water content and degassing of silicic andesites from recent Plinian and dome-forming eruptions at Mount Pelée volcano (Martinique, Lesser Antilles arc). J. Volcanol. Geotherm. Res. 96, 191-206.

Martel, C., Champallier, R., Prouteau, G., Pichavant, M., Arbaret, L., Balcone-Boissard, H., Boudon, G., Boivin, P., Bourdier, J.-L., Scaillet, B., 2013. Trachyte Phase Relations and Implication for Magma Storage Conditions in the Chaîne des Puys (French Massif Central). J. Petrol. 54, 1071-1107. https://doi.org/10.1093/petrology/egt006 
Martel, C., Schmidt, B.C., 2003. Decompression experiments as an insight into ascent rates of silicic magmas. Contrib. Mineral. Petrol. 144, 397-415.

Mason, R.M., Starostin, A.B., Melnik, O.E., Sparks, R.S.J., 2006. From Vulcanian explosions to sustained explosive eruptions: The role of diffusive mass transfer in conduit flow dynamics. J. Volcanol. Geotherm. Res. 153, 148-165.

Mattews, S.J., Gardeweg, M.C., Sparks, R.S.J., 1997. The 1984 to 1996 cyclic activity of Lascar Volcano, northern Chile: cycles of dome growth, dome subsidence, degassing and explosive eruptions. Bull. Volcanol. 59, 72-82.

Melnik, O.E., Blundy, J.D., Rust, A.C., Muir, D.D., 2011. Subvolcanic plumbing systems imaged through crystal size distributions. Geology 39, 403-406.

Miwa, T., Geshi, N., 2012. Decompression rate of magma at fragmentation: Inference from broken crystals in pumice of vulcanian eruption. J. Volcanol. Geotherm. Res. 227-228, 76-84.

Moitra, P., Gonnermann, H.M., Houghton, B.F., Giachetti, T., 2013. Relating vesicle shapes in pyroclasts to eruption styles. Bull. Volcanol. 75, 691.

Muir, D.D., Blundy, J.D., Rust, A.C., 2012. Multiphase petrography of volcanic rocks using element maps: a method applied to Mount St. Helens, 1980-2005. Bull. 'olcanol. 74, 1101-1120. https://doi.org/10.1007/s00445-012-0586-0

Mujin, M., Nakamura, M., 2014. A nanolite record of eruption strle ......sition. Geology 42, 611-614. https://doi.org/10.1130/G35553.1

Murch, A.P., Cole, P.D., 2019. Using microlites to gain insig ${ }^{1}$ ts $111 \mathrm{t}$ ascent conditions of differing styles of volcanism at Soufrière Hills Volcano. J. ' 'v' 'aı 'Jl. Geotherm. Res. 384, 221-231. https://doi.org/10.1016/j.jvolgeores.2019.07.022

Nadeau, O., Williams-Jones, A.E., Stix, J., 2013. Magma ic-h Jrothermal evolution and devolatilization beneath Merapi volcano, In' on siria. J. Volcanol. Geotherm. Res. 261, 50-68.

Pistolesi, M., Cioni, R., Bonadonna, C., Elissondo N. P uumann, V., Bertagnini, A., Chiari, L., Gonzales, R., Rosi, M., Francalanci, I., ?. : 5 . Complex dynamics of small-moderate volcanic events: the example of the 2011 rhy litj Cordón Caulle eruption, Chile. Bull. Volcanol. 77, 3. https://doi.org/10.1007/s00445-014-`'998-3

Pleše, P., Higgins, M.D., Baker, D.R., Ku ${ }^{\top}$ rna Prašek, M., 2019a. Nucleation and growth of bubbles on plagioclase crystals during e $\mathrm{e}_{\mathrm{r}}$,rin ental decompression degassing of andesitic melts. J. Volcanol. Geotherm. Res. 388, 1r,6t/19. https://doi.org/10.1016/j.jvolgeores.2019.106679

Pleše, P., Higgins, M.D., Baker, D.P., эnıafame, G., Kudrna Prašek, M., Mancini, L., Rooyakkers, S.M., 2019b. Production s nu tetachment of oxide crystal shells on bubble walls during experimental vesiculation if andesitic magmas. Contrib. Mineral. Petrol. 174, 21. https://doi.org/10.1007/su'110-019-1556-8

Pleše, P., Higgins, M.D., Mancı. i L., Lanzafame, G., Brun, F., Fife, J.L., Casselman, J., Baker, D.R., 2018. Dynamic ob ervi tions of vesiculation reveal the role of silicate crystals in bubble nucleation and $\mathrm{g}_{1}$ 'w iu in andesitic magmas. Lithos 296-299, 532-546. https://doi.org/10.11 16/j.lithos.2017.11.024

Preece, K., Gertisser, R., Barclay, J., Berlo, K., Herd, R.A., Edinburgh Ion Microprobe Facility, -, 2014. Pre- and syn-eruptive degassing and crystallisation processes of the 2010 and 2006 eruptions of Merapi volcano, Indonesia. Contrib. Mineral. Petrol. 168, 1061.

Richard, D., Scheu, B., Mueller, S.P., Spieler, O., Dingwell, D.B., 2013. Outgassing: Influence on speed of magma fragmentation. J. Geophys. Res. Solid Earth 118, 862-877. https://doi.org/10.1002/jgrb.50080

Sano, K., Wada, K., Sato, E., 2015. Rates of water exsolution and magma ascent inferred from microstructures and chemical analyses of the Tokachi-Ishizawa obsidian lava, Shirataki, northern Hokkaido, Japan. J. Volcanol. Geotherm. Res. 292, 29-40. https://doi.org/10.1016/j.jvolgeores.2014.11.015

Schindelin, J., Arganda-Carreras, I., Frise, E., Kaynig, V., Longair, M., Pietzsch, T., Preibisch, S., Rueden, C., Saalfeld, S., Schmid, B., Tinevez, J.-Y., White, D.J., Hartenstein, V., Eliceiri, K., 
Tomancak, P., Cardona, A., 2012. Fiji: an open-source platform for biological-image analysis. Nat. Methods 9, 676-682. https://doi.org/10.1038/nmeth.2019

Shea, T., 2017. Bubble nucleation in magmas: A dominantly heterogeneous process? J. Volcanol.

Geotherm. Res. 343, 155-170. https://doi.org/10.1016/j.jvolgeores.2017.06.025

Shea, T., Gurioli, L., Larsen, J.F., Houghton, B.F., Hammer, J.E., Cashman, K.V., 2010. Linking experimental and natural vesicle textures in Vesuvius 79 AD white pumice. J. Volcanol. Geotherm. Res. 192, 69-84.

Sparks, R.S.J., Gardeweg, M.C., Calder, E.S., Matthews, S.J., 1997. Erosion by pyroclastic flows on Lascar Volcano, Chile. Bull. Volcanol. 58, 557-565. https://doi.org/10.1007/s004450050162

Stampanoni, M., Groso, A., Isenegger, A., Mikuljan, G., Chen, Q., Bertrand, A., Henein, S., Betemps, R., Frommherz, U., Böhler, P., Meister, D., Lange, M., Abela, R., 2006. Trends in synchrotron-based tomographic imaging: the SLS experience, in: Developments in X-Ray Tomography V. Presented at the Developments in X-Ray Tomography V, International Society for Optics and Photonics, p. 63180M. https://doi.org/10.1117/12.679497

Suzuki, Y., Fujii, T., 2010. Effect of syneruptive decompression patl $\mathrm{cn}$ shifting intensity in basaltic sub-Plinian eruption: Implication of microlites in Yufune-2 sco ${ }^{\circ}$ ๆ from Fuji volcano, Japan. J. Volcanol. Geotherm. Res. 198, 158-176. https://doi.org/1C 101 ₹/j.jvolgeores.2010.08.020

Taisne, B., Jaupart, C., 2008. Magma degassing and intermittent ${ }^{1} \mathbf{v}_{\mathbf{a}}{ }^{J} \mathrm{~J} m e$ growth. Geophys. Res. Lett. 35.

Toramaru, A., 2006. BND (bubble number density) decompr 'sion rate meter for explosive volcanic eruptions. J. Volcanol. Geotherm. Res. 154, 303-? ‘ú

Toramaru, A., 1995. Numerical study of nucleation and $\mathrm{g}_{1}$ 'wth of bubbles in viscous magmas. J. Geophys. Res. 100, 1913-1931.

Toramaru, A., Noguchi, S., Oyoshihara, S., Tsune, F ., J08. MND(microlite number density) water exsolution rate meter. J. Volcanol. Geothe $\mathrm{m}_{\text {. }}$ Re s., Scientific drilling at Mount Unzen 175,

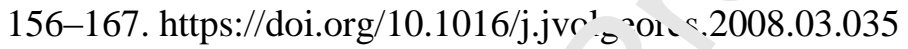

Venezky, D.Y., Rutherford, M.J., 1999. Pet: lor y and Fe-Ti oxide reequilibration of the 1991 Mount Unzen mixed magma. J. Volcanol. Gec herm. Res. 89, 213-230.

Widiyantoro, S., Ramdhan, M., Métaxiaı, I.-P., Cummins, P.R., Martel, C., Erdmann, S., Nugraha, A.D., Budi-Santoso, A., Laurin ^ r r hmi, A.A., 2018. Seismic imaging and petrology explain highly explosive eruptivr s c 1 Merapi Volcano, Indonesia. Sci. Rep. 8. https://doi.org/10.1038/s415 fo 1 1 o-31293-w

Wright, H.M.N., Weinberg, R.F., ? $\iota^{\mathrm{9}}$. Strain localization in vesicular magma: Implications for rheology and fragmentatic: Geology 37, 1023-1026. 


\section{Figure Captions}

Figure 1: Three $\square$ dimensional cumulative (open circles) and non $\square$ cumulative (gray bars) oxide size distributions in experimental sample ABG28. The two vertical black lines indicate the lower limits of detection of the other experimental samples.

Figure 2: Oxide connectivity (fraction of oxides connected to vesicles) as a function of VOI size. The counting method in each VOI used object centroids (see Fig. S3 for details). VOIs of natural samples $>10^{8}$ voxels are statistically rep 'sentative of connectivity. VOIs of experimental samples $>10^{7}$ voxels are statistica. ${ }^{1} \mathrm{~V} r$ presentative of connectivity. Dimensions of the largest VOIs are given in Tabl 2 ?

Figure 3: Vesicle number density (VND) as a functı. of oxide number density (OND) of two characteristic samples that were studi $r$. $\mathrm{u}$;ing different methods. Intrinsic errors are smaller than the symbols.

Figure 4: Representative SEM and hresholded images of natural products. Our procedure distinguishes four type of ¿jjects (vesicles, oxides, other crystals, and glass). SEM images occupy the $u_{1}$, ner ieft parts and thresholded images occupy the lower right parts. Horizontal white e bars are $100 \mu \mathrm{m}$ long. A) Vesicular texture (AMO36B). B) Diktytaxitıc ex....e (AMO16C1). C) Intermediate texture (1448).

Figure 5: Levels of oxide-vesicle (x-axis) and vesicle-oxide (y-axis) connectivity reported as proportion of objects in contact. Insets illustrate four pairs of connectivity levels (black squares are oxides and gray disks are vesicles). Open triangles represent natural samples sorted by texture: diktytaxitic (“dik.") and pumiceous (“other"). Black triangles represent experimental samples. Errors smaller than symbols are not shown. 
Figure 6: Representative 3D and slice renderings from $\mu \mathrm{CT}$ scans of experimental and natural products. A) Grayscale slice of natural sample AMO29. Vesicles are dark gray; glass and plagioclase share a similar medium gray shade; pyroxene and amphibole share a similar shade of light gray, and oxides are white. Scale bar is $1 \mathrm{~mm}$. B) Natural sample AMO29. Oxides are red, glass and other minerals are blue, and vesicles are transparent. Scale bar is $100 \mu \mathrm{m}$. C) Experimental sample ABG16. Vesicles are blue, oxides are red, and glass is transparent. Scale bar is $50 \mu \mathrm{m}$.

Figure 7: Vesicle number density (VND) as a function of nxa number density (OND) of

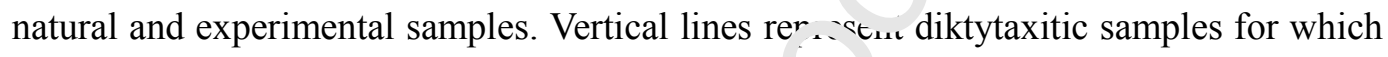
only ONDs are reported. A) Experimental data Errors associated to the Burgisser and Gardner (2004) samples are smaller than he symbols. B) Eruptions dominated by vertical explosions. SHV stands for So itr èe Hills volcano samples and BAF stands for block-and-ash flow samples. Ve in al ¿ rors bars of the Kilian samples extend from the VND of the full vesicle populat $n$ (open squares) down to that including only the smallest vesicles (Colombi $\ldots$ st a.., 2017). Black error bars indicate typical errors (see the Methods section). C) Fru ${ }_{\mathrm{r}}{ }^{\mathrm{i}}$ ions dominated by dome collapse. Black error bars indicate typical errors.

Figure 8: OND as a fun tion of the pressure difference between the reservoir and the conduit. Pre-explosive onduit storage pressures for Soufrière Hills (SHV, triangles) are from Burgisser et al. (2010) for the 1997 explosions, from Burgisser et al. (2019) for the 2010 explosion, and from Table S1 for the 2006 block-and-ash flow. Pressures for Kilian (squares) are from Colombier et al. (2017) and pressures for Merapi (circles) are from Drignon et al. (2016). Errors on pressures were omitted for clarity.

Figure 9: Syn-explosive decompression rates from VND as a function of pre-explosive storage 
pressure for Soufrière Hills (SHV), Kilian (Colombier et al., 2017), and Merapi volcanoes. Errors were omitted for clarity.

Figure 10: OND (top axis) and crystallization rate (bottom axis) as a function of pre-explosive storage pressures. A) Data from two series of Vulcanian events (1997 and 2010) at Soufrière Hills volcano. Crystallization curves are given for magnetite and ilmenite. B) Data from two events (Vulcanian on Oct. 26 and sub-Plinian on Nov. 5) at Merapi volcano. Magnetite is the only precipitating oxide. Crystallization curves are given for each of the three magmas involved in the eruption (deen $\operatorname{sh}^{-1}{ }^{-1}$ low, and recharge).

Figure 11: Frequency distribution of ascent rates stem ring from the Toramaru et al. (2008) decompression meter (Text S5). Ascent $r$ tes are calculated from individual OND determinations at the melt water contents an $\lrcorner$ mic slite nucleation pressures indicated. A) Soufrière Hills volcano. B) Merapi vc ica....

Figure 12: Ascent dynamics at Kilian volu ?no. A) OND (top axis) and magnetite crystallization rate (bottom axis) as a fur $\mathrm{el} \cap \eta$ of pre-explosive storage pressures. Initial conditions of the rhyolite-MELTS ri is a a $^{-}$given in Supplementary Text S4. B) Frequency distribution of ascent rates ster. $\eta \mathrm{H}_{\complement}$, from the Toramaru et al. (2008) decompression meter (Text S5). 


\section{Credits author statement}

AB, LA, CM: Conceptualization, Investigation; MF, MC: Investigation; All : Writing - Review \& Editing 


\section{Declaration of interests}

$\bigotimes$ The authors declare that they have no known competing financial interests or personal relationships that could have appeared to influence the work reported in this paper.

$\square$ The authors declare the following financial interests/personal relationships which may be considered as potential competing interests: 
Highlights

- Measures of oxide microlites number densities in products of silicic eruptions are scarce.

- We measured oxide and vesicle number densities in experiments and at five volcanoes.

- Heterogeneous nucleation models only work when oxides are at least as numerous as vesicles.

- Ascent rates needed to nucleate oxides overlap those characteristic of the effusiveexplosive transition.

- The appearance of oxides in the conduit is a primer for explosive behavior. 


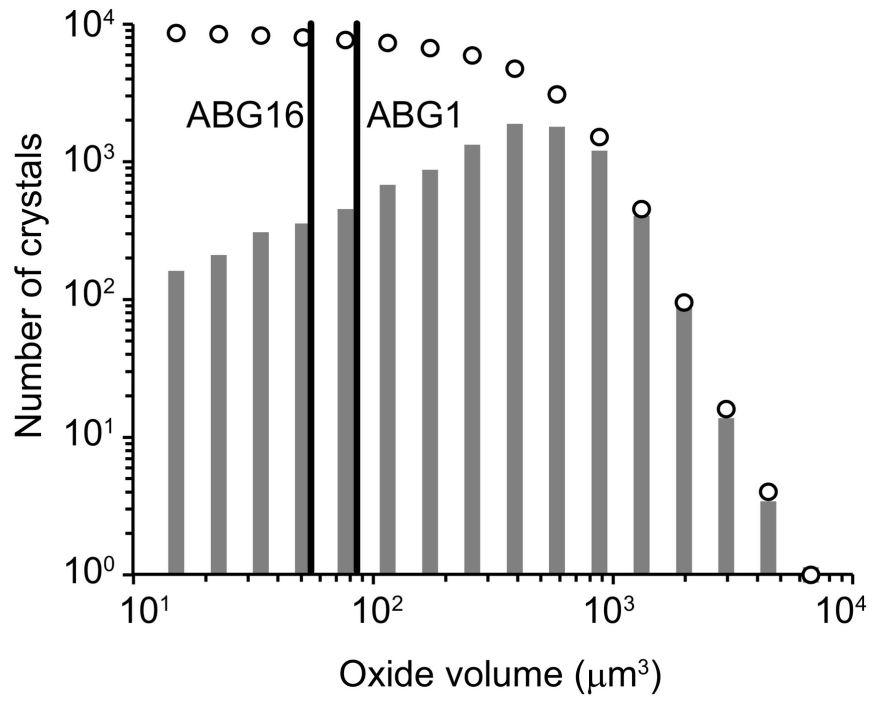

Figure 1 


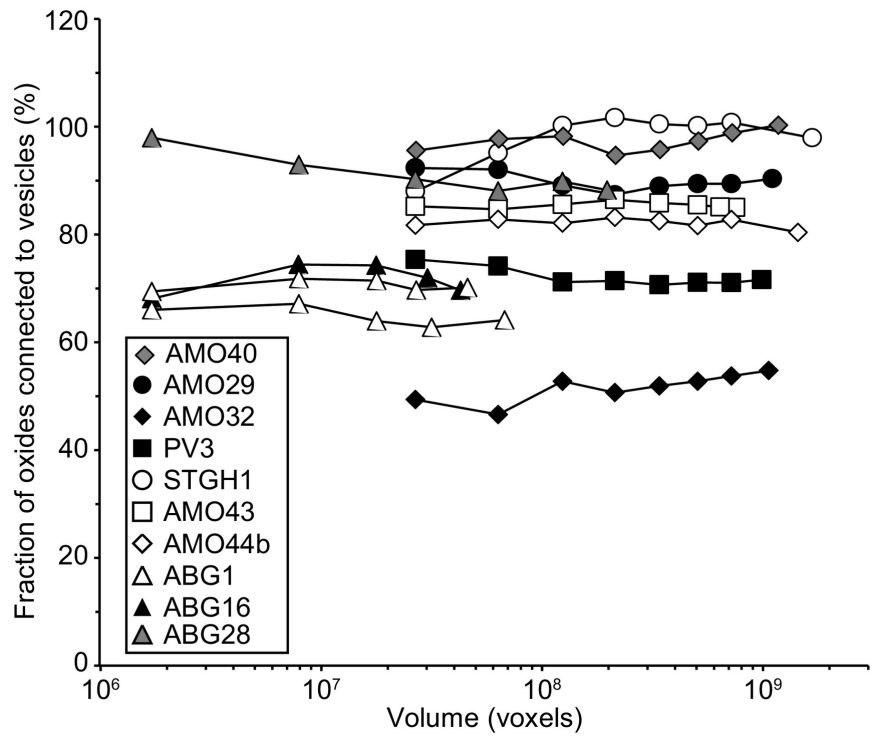

Figure 2 


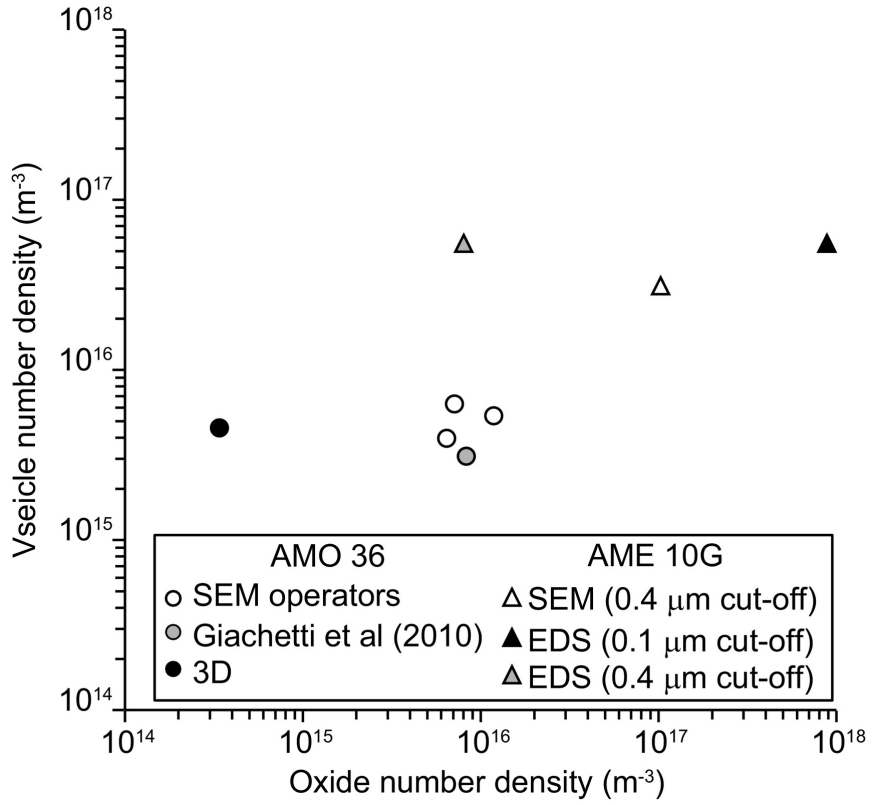

Figure 3 

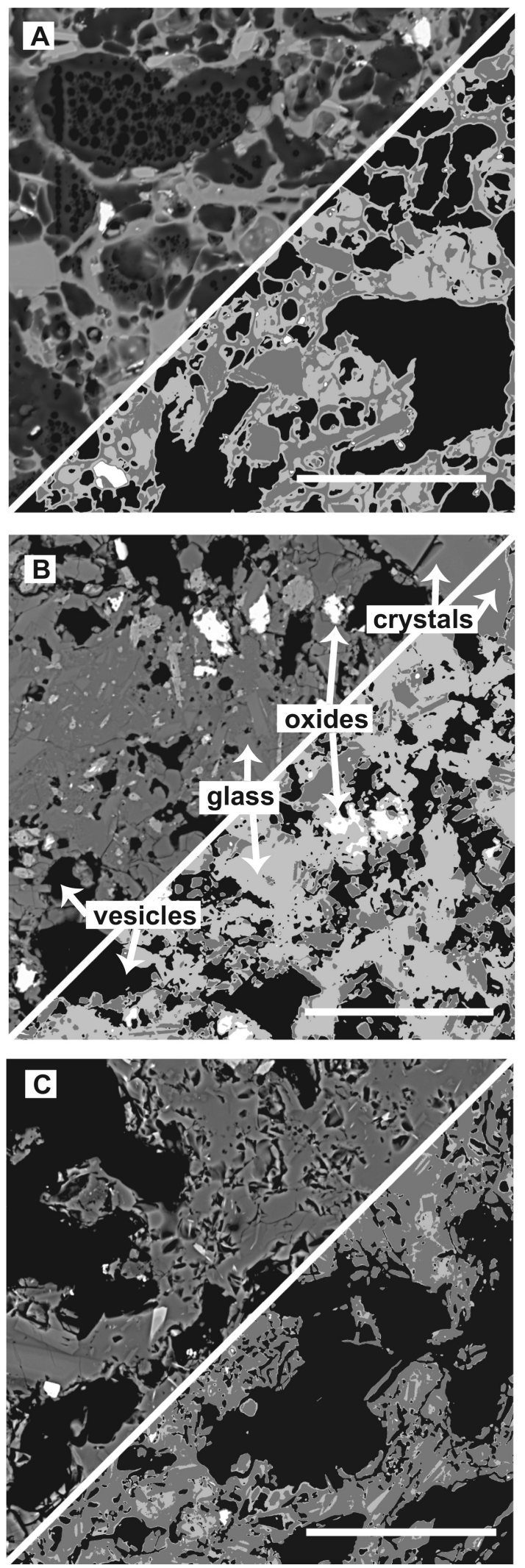


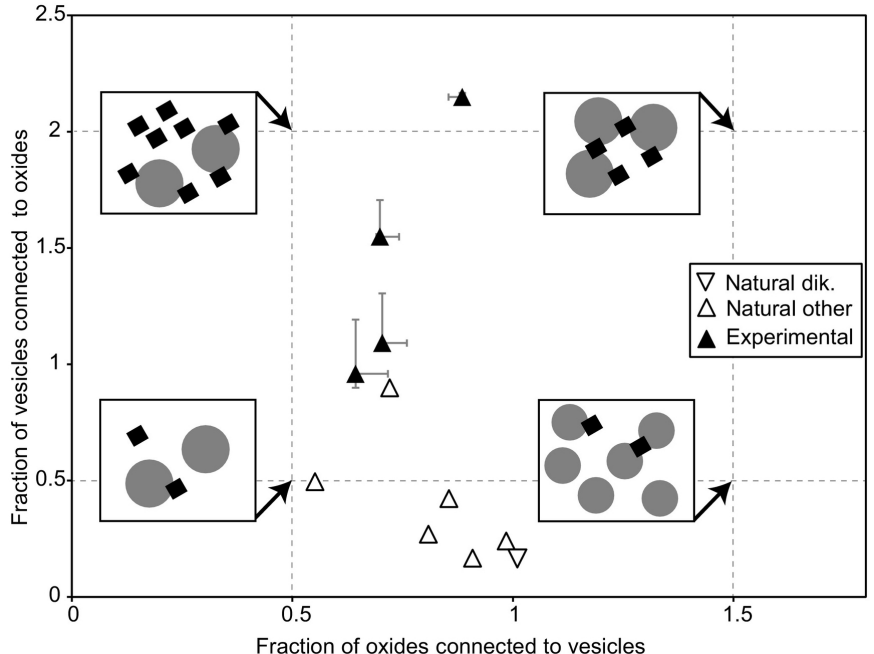

Figure 5 

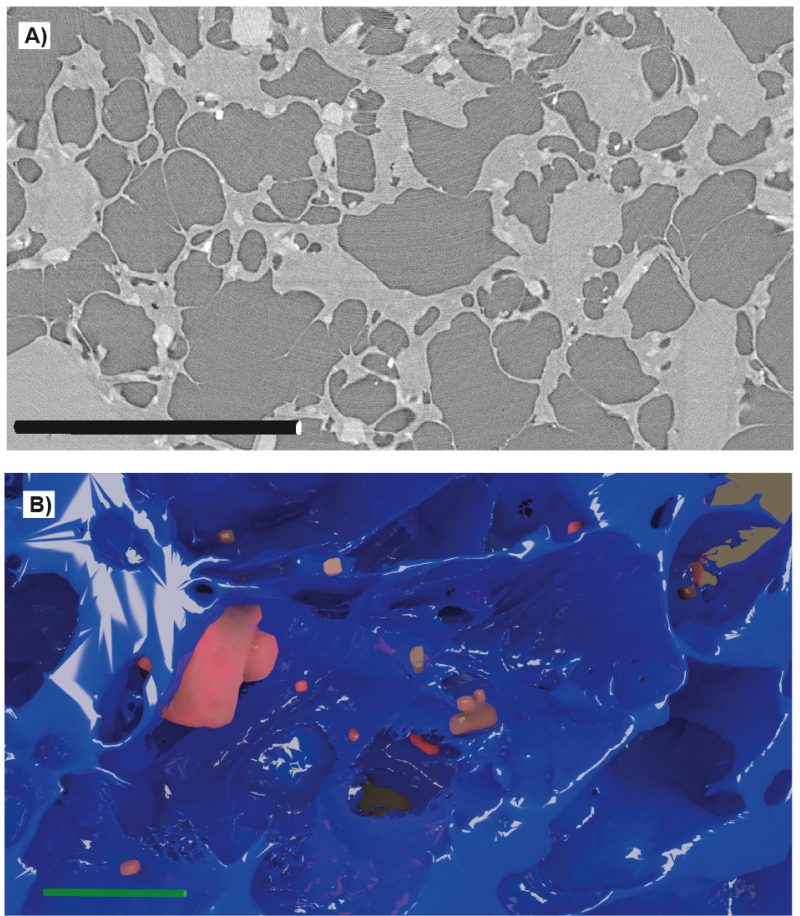

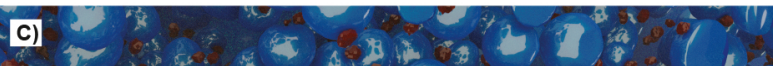

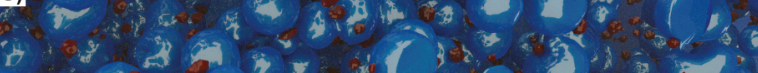

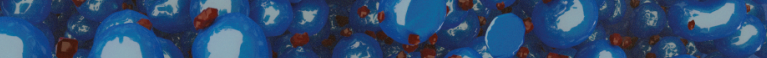

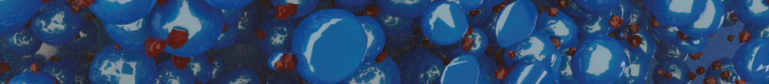

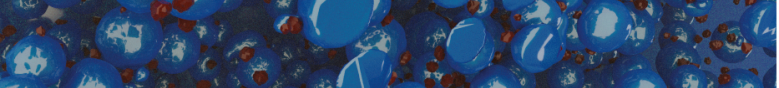

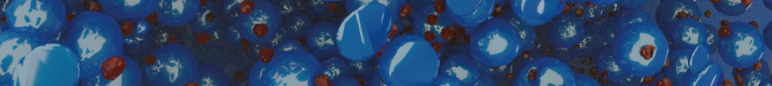

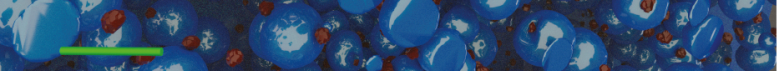

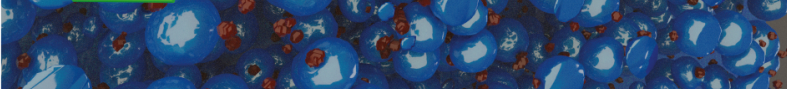

Figure 6 

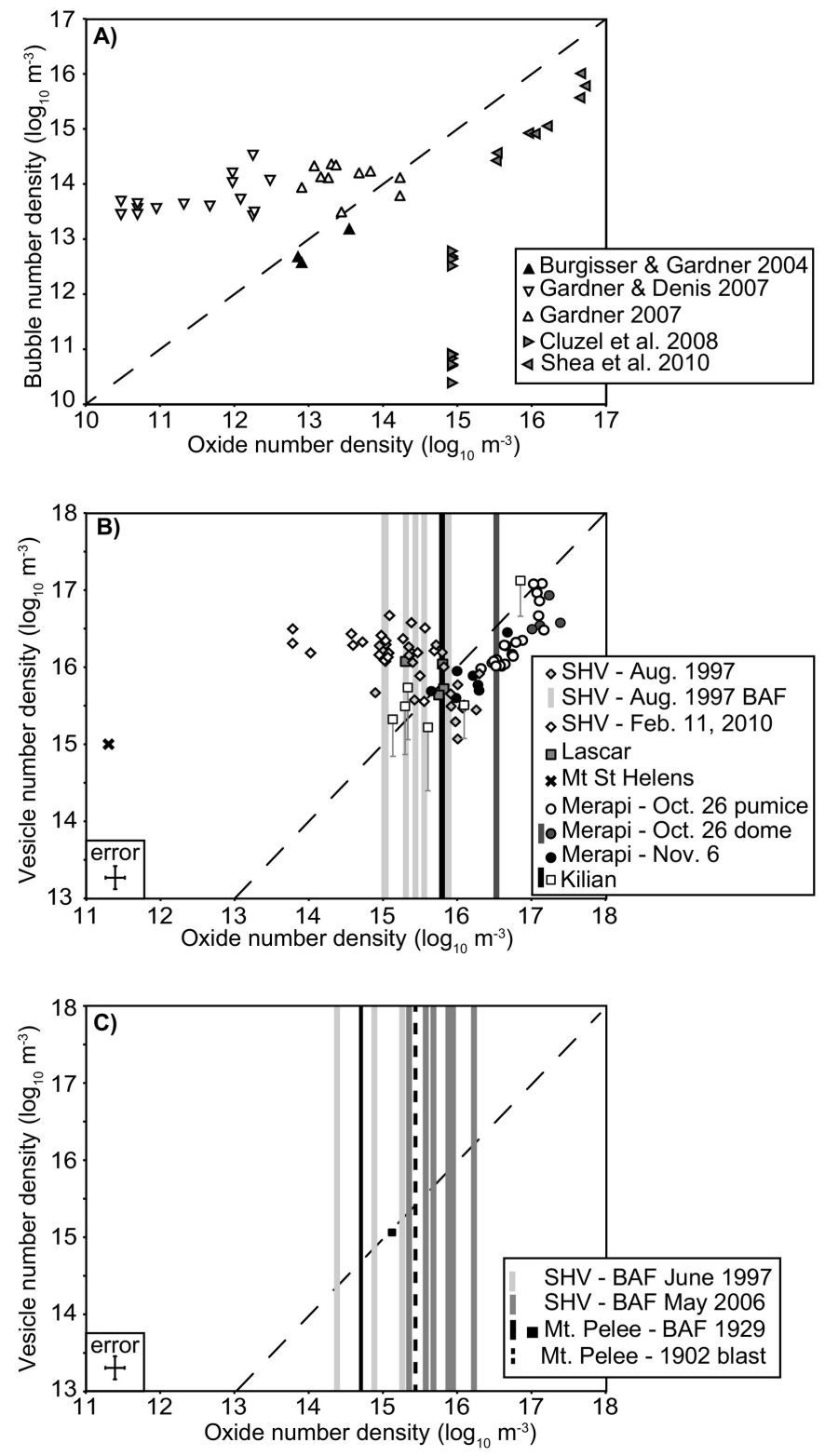

Figure 7 


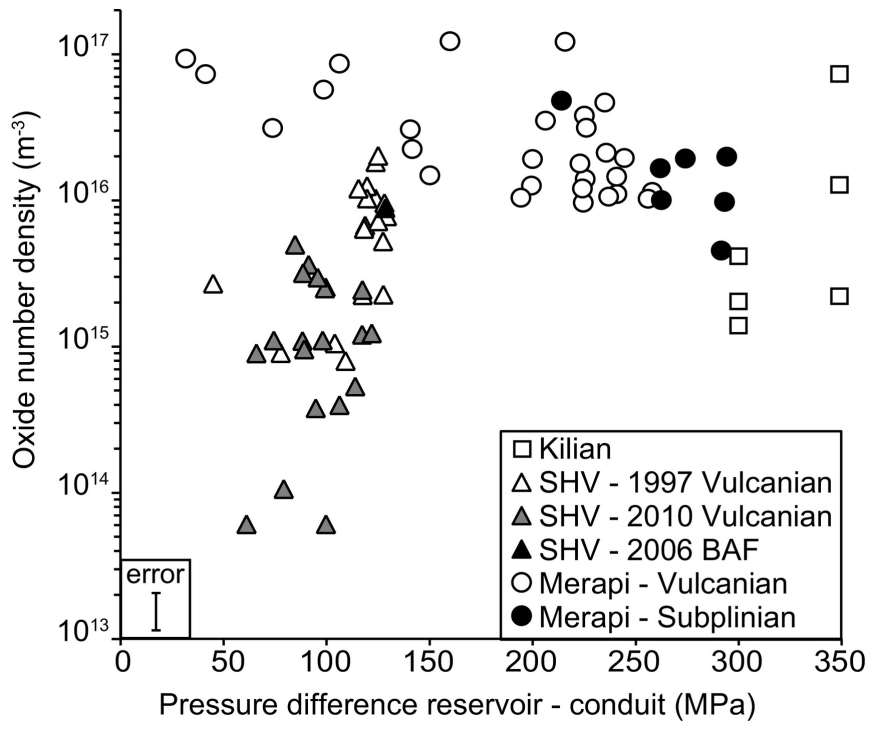

Figure 8 


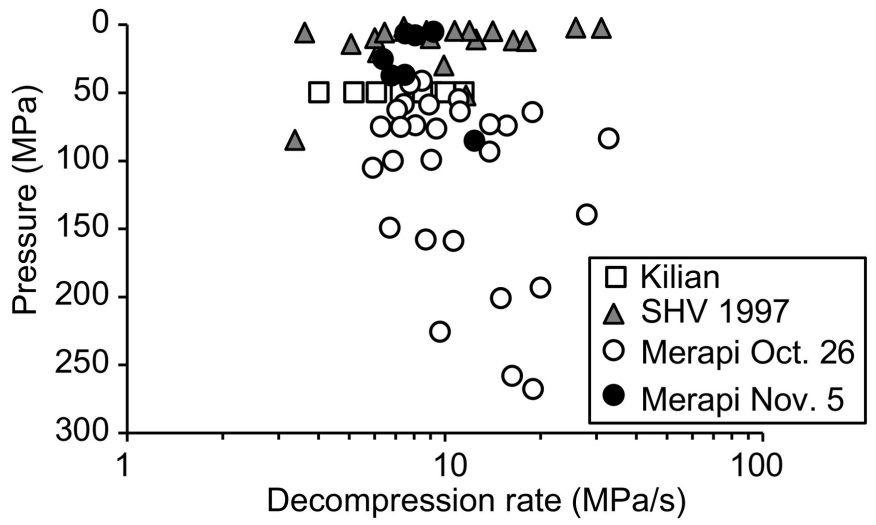

Figure 9 

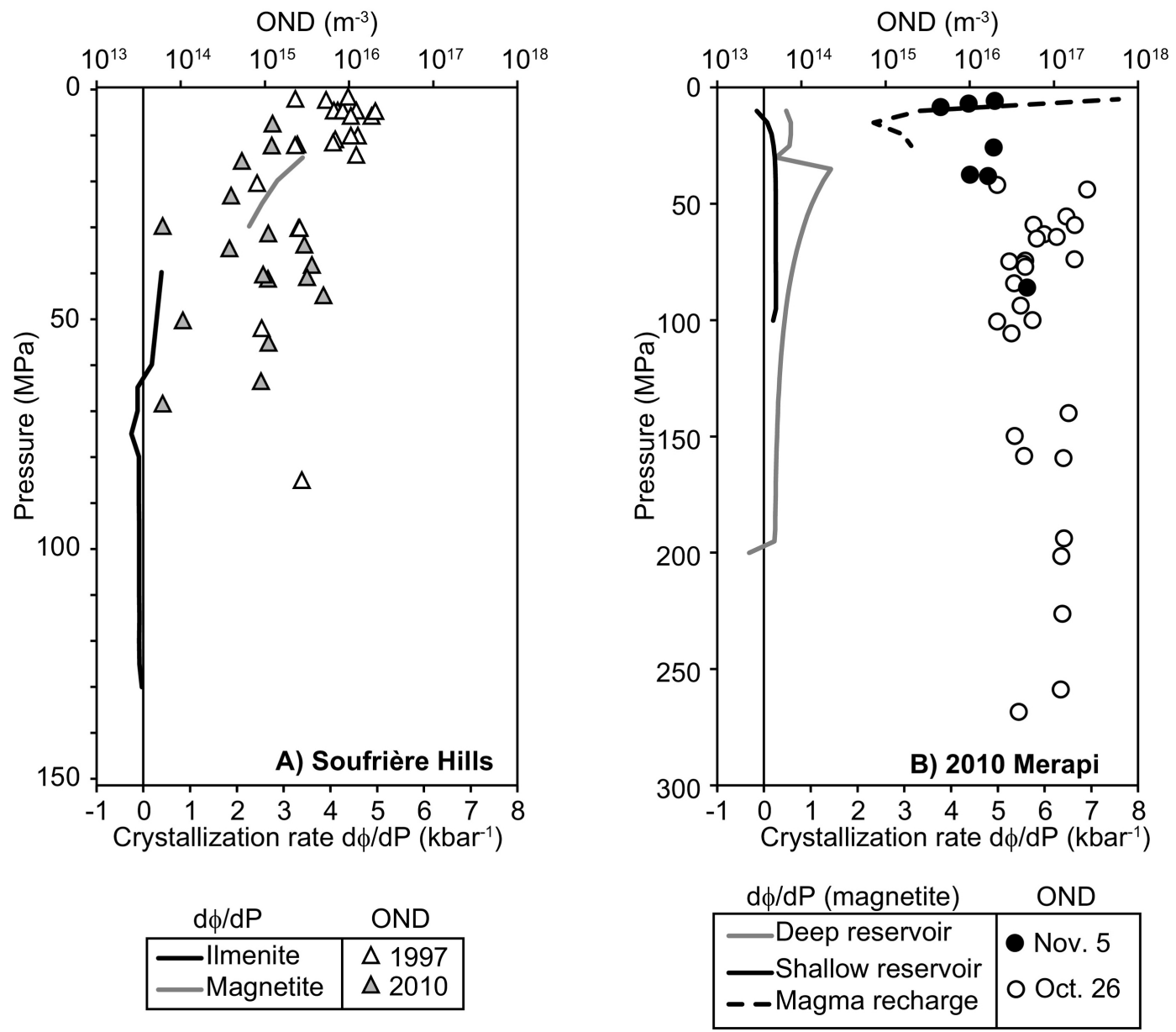
A) Soufrière Hills

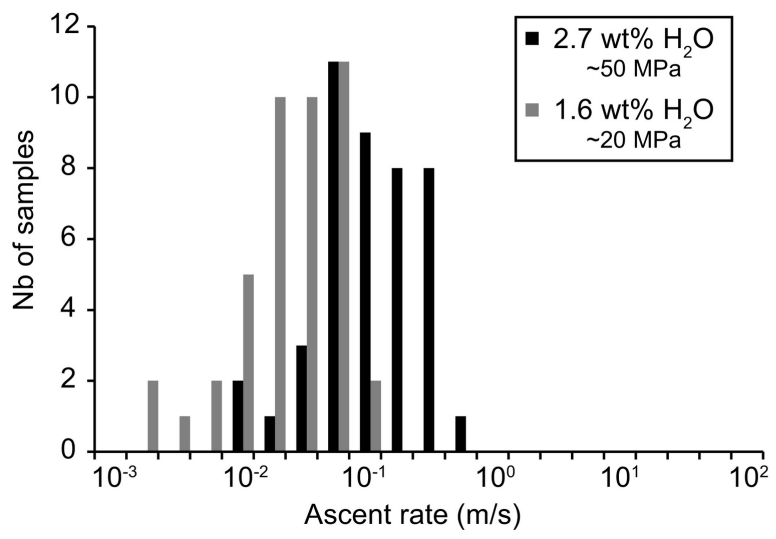

B) Merapi

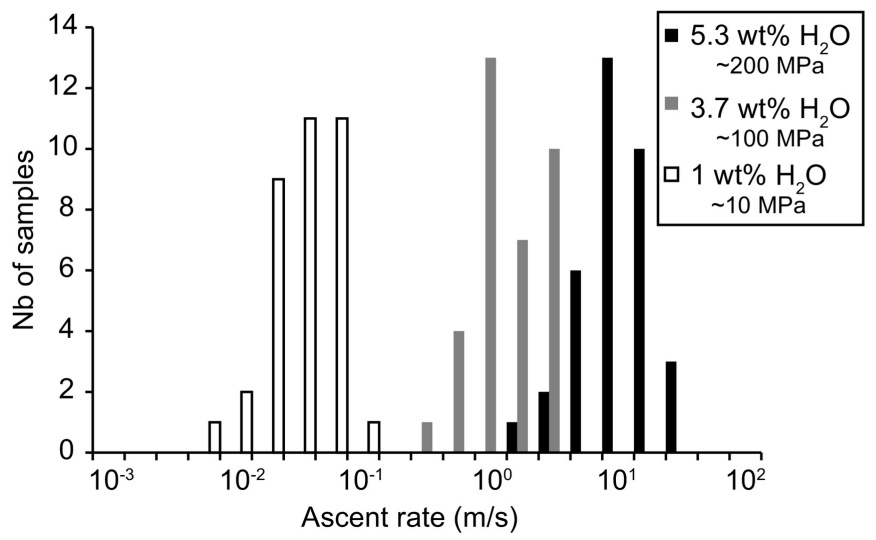

Figure 11 


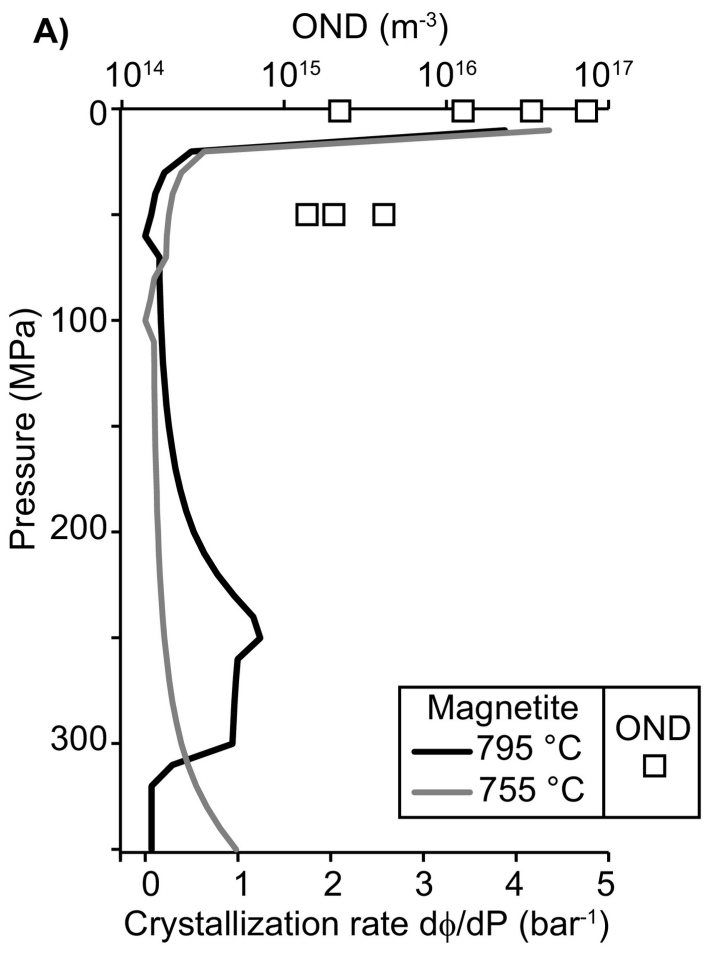

B)

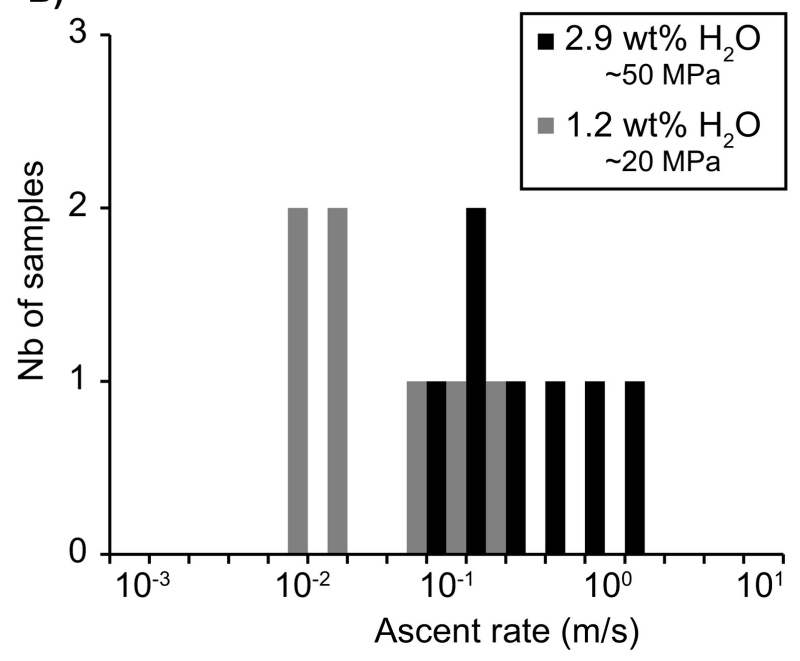

